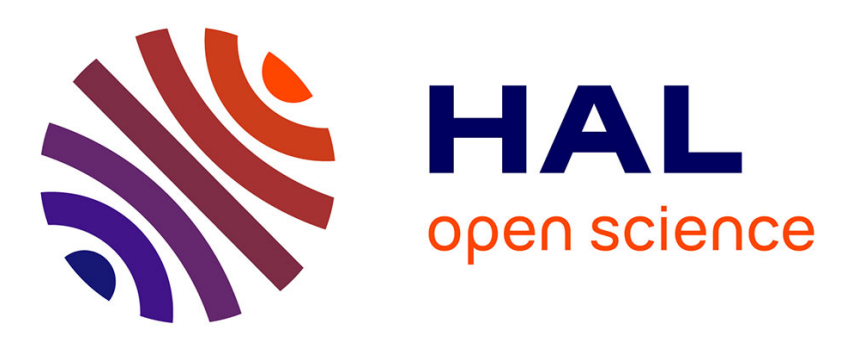

\title{
Tensile post-impact behaviour of thin carbon/epoxy and glass/epoxy hybrid woven laminates - Part I: Experimental study
}

\author{
A. Rogani, Pablo Navarro, Steven Marguet, Jean-François Ferrero, C. \\ Lanouette
}

\section{To cite this version:}

A. Rogani, Pablo Navarro, Steven Marguet, Jean-François Ferrero, C. Lanouette. Tensile post-impact behaviour of thin carbon/epoxy and glass/epoxy hybrid woven laminates - Part I: Experimental study. Composite Structures, 2019, 230, pp.111508. 10.1016/j.compstruct.2019.111508 . hal-02305922

\section{HAL Id: hal-02305922 \\ https://hal.science/hal-02305922}

Submitted on 9 Oct 2019

HAL is a multi-disciplinary open access archive for the deposit and dissemination of scientific research documents, whether they are published or not. The documents may come from teaching and research institutions in France or abroad, or from public or private research centers.
L'archive ouverte pluridisciplinaire HAL, est destinée au dépôt et à la diffusion de documents scientifiques de niveau recherche, publiés ou non, émanant des établissements d'enseignement et de recherche français ou étrangers, des laboratoires publics ou privés. 


\title{
Tensile post-impact behaviour of thin carbon/epoxy and glass/epoxy hybrid woven laminates - Part I : experimental study
}

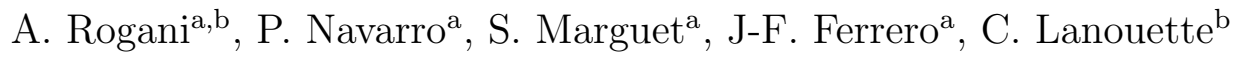 \\ ${ }^{a}$ Université de Toulouse, Institut Clément Ader, UMR CNRS 5312, \\ UPS/INSA/ISAE/Mines Albi, 3 rue Caroline Aigle, 31400 Toulouse, France \\ ${ }^{b}$ Airbus Helicopters, 1 Place du Générale Valérie André, 93440, Dugny, France
}

\begin{abstract}
This article concerns the study of post-impact damage propagation in two thin hybrid woven composite laminates loaded in tension. Low velocity normal drop weight impact tests are first performed. Post-impact quasi-static tensile tests are then carried out and monitored by Digital Image Correlation. The influence of the impact energy variation on the fracture surfaces and the residual strength is studied. In order to have a better understanding of the mechanisms involved into the hybrid laminates, four monomaterial sample configurations are also tested. When the damage after impact is barely visible, the sample behaves as a non-impacted sample. When the damage is visible, it propagates whatever the impact energy. The damage grows in the direction perpendicular to the loading for all the monomaterial laminates while two different damage scenarios are observed for the hybrid laminates. The residual strength evolves in three steps depending on the impact energy : first a very low decrease, then an important drop and finally a plateau.
\end{abstract}

Keywords: Woven composites, thin laminates, post-impact behaviour

\section{Introduction}

This two parts article deals with the post-impact behaviour of thin hybrid woven composite laminates under tensile loading. In this paper, an experimental study is carried out on hybrid and monomaterial woven composite 
samples submitted to a tensile loading after having been impacted with a low velocity in a drop tower device.

Composite structures are widely used, specifically in the field of aeronautics. These structures are known to be very sensitive to impact loadings. Indeed, impacted composites usually present matrix cracking, delamination and fibre breakage. These damages, that can be barely detectable, induce a decrease of the mechanical properties and a loss of the strength. Thus, applying a load on an impacted composite structure can lead to the final failure of the structure and have dramatic consequences. For all these reasons, understanding and characterizing the post-impact behaviour of composite structures, that is to say the growth of the damages induced by impacts, is important.

Post-impact behaviour of unidirectional composite has been widely studied. In particular, the compressive and tensile post-impact behaviour has been investigated $[1,2,3,4,5,6]$. The residual tensile strength versus impact energy evolves in three steps. First, no damage occurs as long as the impact energy is below the damage threshold. Then the residual strength decreases rapidly with the impact energy. Finally, when the impact perforates the laminate, the residual strength remains constant. The critical damage mode is fibre breakage. For the compressive post-impact loadings, the main failure mode is local buckling due to the delamination induced by impact.

Concerning post-impact behaviour of woven laminates, tensile and compressive behaviours have been studied. The compressive behaviour after impact is the most studied because it is the most critical failure mode $[7,8,9,10,11]$. Indeed, the impact generates local delamination that induces micro-buckling of the bundles of fibres that can lead to a total failure. Studies on post-impact tensile behaviour on woven fabric laminates are more recent $[12,13,14,15]$. Most of them are conducted on carbon with layers oriented at $0^{\circ} / 90^{\circ}$. The residual tensile strength decreases with the impact energy, while the global stiffness does not seem to be significantly affected. In these studies, the post-impact strength can be directly connected to the failure of the fibres.

However, all the studies are made on composites made up with only one material. During the recent years, authors started to take an interest in hybrid composites, more specifically in composites composed of two materials or more. The objective is an improvement of the properties and a reduction of the costs. Indeed, the in-plane mechanical properties of hybrid laminates composites can be better than single-material laminates composites. For 
example, adding glass plies to a carbon laminate improves the tensile behaviour as the glass fibres have a greater strain to failure and are more ductile in comparison to carbon fibres $[16,17,18,19,20,21]$. On the contrary, adding carbon plies to a glass laminate increases the tensile stiffness and strength to failure. Concerning the strain to failure of the hybrid laminates, some authors use the term of "hybrid effect" or "synergistic effect" : the value experimentally obtained is greater than that calculated with the rule of mixtures. Furthermore, this hybridization can prevent the catastrophic failure behaviour of carbon fibres. Indeed, some studies show that the final break of hybrid laminates is not sudden but progressive while the failure of the different materials is not simultaneous $[16,17,22]$. It leads also to an improvement of the impact response. As for the tensile behaviour, glass fibres can be added to carbon laminates [23, 18, 24, 25], their strain-rate and strength-rate response being much better. However, in this case, the "hybrid effect" depends on the stacking sequence and the position of the glass plies [26]. Other combinations are also tested as carbon/aramid [27, 28, 29] or carbon/polyethylene fibres [30]. Adding these materials to carbon plies increases the energy absorbed during the impact. Combinations without carbon are also investigated like graphite/glass [31, 32] or graphite/nylon [30] and during the last decade, the use of synthetic and natural fibres (as basalt fibres) to replace carbon or glass fibres has been also studied [33, 34, 35, 36]. Recently, an other type of hybridization has been studied : the same fiber and matrix materials are used but with different layers architectures, for example a combination of woven fabrics and unidirectionnal plies (UD [37, 38]. The impact behaviour in terms of damage extent is improved when UD plies are placed between woven fabrics plies.

The post-impact behaviour of hybrid laminates has been less studied. Concerning the unidectionnal composites, Naik et al. studied the post-impact compressive behaviour of glass-carbon/epoxy laminates [39] and Petrucci et al. worked on the flexural behaviour of glass-basalt/epoxy hybrid laminates [36]. For woven composites, Dehkordi et al. studied the post-impact compressive behaviour of basalt-nylon laminates [40] while other authors investigated the flexural behaviour of glass-basalt/epoxy and aramid-basalt hybrid laminates $[33,35]$. Different stacking sequences were compared through these studies. In the end, the authors showed that the hybridization of the material allows a better residual buckling strength for the laminate in compression and a better residual flexural strength for the laminate in bending.

But, neither study deals with the tensile behaviour of an impacted hy- 
brid carbon/glass woven laminate while this material combination has been quite studied in the litterature $[16,17,18,19,20,21,22,23,24,25]$. Thus, this paper focuses on the post-impact damage propagation in two thin hybrid carbon-glass/epoxy woven composite laminates under tensile loading. In parallel, monomaterial carbon/epoxy and glass/epoxy laminates with different ply orientations are also studied. Low velocity impacts are first performed with a drop weight device. Then quasi-static tensile tests are carried out on the impacted samples. Impact energies are varied. The influence of the hybridization, the initial damage and the stacking sequence are investigated. An analysis of the damage scenario based on measures from Digital Image Correlation is provided. The post-impact damage propagation in the hybrid laminate happens to be highly influenced by the presence of a glass ply and by the carbon plies orientations.

\section{Material and samples}

In this study, post-impact tensile behaviour of thin hybrid woven composite laminates is investigated. Two hybrid sample configurations commonly used as skin of helicopter blades, presented in Table 1, are studied. They are made with one ply of glass/epoxy and two plies of carbon/epoxy woven fabrics : $G_{0} C_{45} C_{45}$ is made up of one ply of glass woven oriented at $0^{\circ}$ and two woven carbon plies oriented at $\pm 45^{\circ}, G_{0} C_{45} C_{0}$ is made up of one ply of glass woven at $0^{\circ}$, one ply of carbon woven at $\pm 45^{\circ}$ and one ply of carbon woven at $0^{\circ}$.

In addition, in order to have a better understanding of the mechanisms involved in the post-impact tensile behaviour, four monomaterial sample configurations, that represent parts of the studied hybrid configurations, are also tested. These four configurations, presented in Table 2, are made with two plies of the same material : $C_{0} C_{0}$ is made up of two plies of carbon woven oriented at $0^{\circ}, C_{45} C_{45}$ is made up of two plies of carbon woven at $\pm 45^{\circ}$, $C_{45} C_{0}$ is made up of one ply of carbon woven at $\pm 45^{\circ}$ and one ply of carbon woven at $0^{\circ}$ and $G_{0} G_{0}$ is made up of two plies of glass woven oriented at $0^{\circ}$.

The samples have been designed to be able to perform low velocity impact tests and tensile tests on the same specimen. The geometry is presented in Figure 1. The dimensions are $100 \mathrm{~mm} \times 300 \mathrm{~mm}$ with a thickness of $0.62 \mathrm{~mm}$ $\left(G_{0} G_{0}\right), 0.71 \mathrm{~mm}\left(C_{0} C_{0}, C_{45} C_{45}, C_{45} C_{0}\right)$ or $1.02 \mathrm{~mm}\left(G_{0} C_{45} C_{45}, G_{0} C_{45} C_{0}\right)$. The tabs are made with three plies of glass/epoxy woven fabrics oriented at $\pm 45^{\circ}$. 


\section{Low velocity impact tests}

The experiments are conducted in two steps. First an impact damage is produced in the samples, then tensile tests are carried out.

The low velocity impact tests are performed with a drop weight device. The impactor has a mass of $2 \mathrm{~kg}$ and a $16 \mathrm{~mm}$ diameter hemispherical steel head. The samples are clamped on a $75 \mathrm{~mm}$ x $125 \mathrm{~mm}$ rectangular frame. The reaction force and the impactor displacement are recorded during the impact. Impact velocities and corresponding impact energies are varied. The values are given in Table 3 .

Figures 2-7 show the fracture surfaces of the impacted samples for all the configurations. The values in yellow represent the size of the damaged zone on the upper ply and the values in white represent the size of the fibres breaks observed in the top and bottom plies.

For the $C_{0} C_{0}$ configuration, no visible damage is observed for the laminate impacted with an energy of $1 \mathrm{~J}$. For higher impact energies, cross-shaped failures oriented in the direction of the fibres are observed. The sizes of the damage increase with the energy of impact until an energy of $4 \mathrm{~J}$. Indeed, for the impacts higher than $4 \mathrm{~J}$ the impactor totally perforates the sample. For the $C_{45} C_{45}$ configuration, there is practically no visible damage for an impact with an energy of $2.25 \mathrm{~J}$. The sizes of the damage increase with the energy of impact. Until $4 \mathrm{~J}$, the impactor rebounds and from $6.25 \mathrm{~J}$, it completely perforates the sample. For the $C_{45} C_{0}$ configuration, there is no visible damage for an energy of impact of 1J. The size of the damage increases with the energy of impact until an energy of $4 \mathrm{~J}$, which corresponds to the perforation of the sample by the impactor with no rebound. The directions of the breaks of fibres are between $\pm 45^{\circ}$ and $0^{\circ} / 90^{\circ}$ in the upper ply and are $0^{\circ} / 90^{\circ}$ in the lower ply. The damage mainly follows the directions of the lower ply in which the damage initiates during the impact. For the $G_{0} G_{0}$ configuration, no visible damage is observed until an energy of $4 \mathrm{~J}$. Then, the sizes of the damage increases with the energy of impact until $6.25 \mathrm{~J}$, which corresponds to the energy from which the impactor totally perforates the sample. The difference with the carbon woven configurations in terms of impact energies are explained by a lower stiffness and a strong dynamic effect for the glass woven, which leads to an increase of the breaking limit with the strain rate $[41,42]$.

For the $G_{0} C_{45} C_{45}$ configuration, the damage is barely visible for an energy of $1 \mathrm{~J}$. Then, the damage increases until $6.25 \mathrm{~J}$ and a rebound of the impactor 
is observed. Carbon fibre failures are noticed in the lower ply and the resin of the upper ply is damaged. For the impact energy of $6.25 \mathrm{~J}$, slight fibre breaks are noticed in the upper ply. Finally for the $9 \mathrm{~J}$ and $16 \mathrm{~J}$ tests, the impactor perforates the three plies so that the damage size is the same for the two impacts. These observations are the same for the $G_{0} C_{45} C_{0}$ configuration : the fibres breaks in the glass ply and the carbon ply and the resin damaging in the glass ply increases with the energy of impact. The damage starts to be really visible for $4 \mathrm{~J}$. The fibres breaks appear in the lower carbon ply at $2.25 \mathrm{~J}$ and in the glass ply at $6.25 \mathrm{~J}$. For $9 \mathrm{~J}$ and $16 \mathrm{~J}$, the impactor completely perforates the three plies and the damages are similar. Finally, for the two hybrid laminates, the add of the glass ply $G_{0}$ leads to a decrease of the damage size in the carbon plies.

\section{Post-impact tensile tests}

In this section, the behavior of the impacted samples under tensile loading is described and analysed. Quasi-static tensile tests on damaged samples are conducted with an INSTRON machine equipped with a load cell of $250 \mathrm{kN}$ at $2 \mathrm{~mm} / \mathrm{min}$ (Figure 8). The reaction load and the displacement of the crosshead are measured during the test. The strain fields in the samples are measured by the use of Digital Image Correlation (DIC). The tests are recorded with two cameras, placed in front and behind the sample.

The residual normalized tensile strength versus impact energy is given in Figure 9. For all the configurations, the curves can be divided in three parts. First, for very small impact energies, no loss of strength is observed. In fact, practically no damage is visible after the impact, so the residual strength seems to be unaffected. Then, an important loss of strength is noticed when the impact energy increases. Finally, the value of the residual strength remains constant with the impact energy. Indeed, after a given impact energy, the impact damage size does not grow, so that the residual strength is not altered. Figure 9 also shows that the relative loss of strength is higher when the plies are oriented at $0^{\circ} / 90^{\circ}$, especially for the glass configuration, which the post-impact tensile behaviour seems to be more sensitive to the impact damage.

In the next paragraphs, the mechanisms leading to the failure, deduced from DIC measurements and fracture shape observations, are analyzed, first for the monomaterial configurations, then for the hybrid configurations. 


\subsection{Monomaterial samples}

\subsection{1. $C_{0} C_{0}$ samples}

Figure 10 shows the fracture surfaces obtained after the quasi-static tensile tests for each energy of impact and Figure 11 regroups the corresponding load/displacement curves. Except for $1 \mathrm{~J}$ impacted sample, for all the other impacted sample, the fracture surfaces are the same whatever the energy of impact used : the final break of the sample is horizontal and the two plies break at the same time. The $1 \mathrm{~J}$ impacted sample has the same behaviour as the clean sample. In that case, the damage is not important enough to propagate (Figure 2) and it breaks for a displacement similar to the clean sample (Figure 11).

An analyze of the damage propagation, based on DIC measures, is made. The strains fields are identical in the two plies (Figure 12) and the first damage propagation appears simultaneously in these two plies just before the final break. The strain field in the load direction $\left(\varepsilon_{y y}\right)$ in the area around the post-impact damage is around four times higher than far from the impact location (Figure 12a). The principal strain in these areas is oriented in the direction $\mathrm{y}$ : near the damaged zone, the fibres are loaded in tension. More, in plane shearing $\varepsilon_{x y}$ is also noticed under and above the impact location (Figure 12b). In these areas, the resin is mainly loaded. However, as

the damage propagates in the direction where $\varepsilon_{y y}$ is high, the failure of the laminate is governed by the fibres breakage.

\subsection{2. $C_{45} C_{45}$ samples}

Figure 13 shows the fracture surfaces obtained after the quasi-static tensile tests for each energy of impact and Figure 14 regroups the corresponding curves. As for configuration $C_{0} C_{0}$, all the fracture surfaces are the same whatever the energy of impact used, except for the sample impacted with an energy of $2.25 \mathrm{~J}$ for which the damage generated by impact is barely visible (Figure 3). The final break of the sample is mainly horizontal and the two plies break at the same time (Figure 13). For the $2.25 \mathrm{~J}$ impacted sample, the fracture surface and the load-displacement curve are similar to those of a clean (non-impacted) sample. The initial damage is to small to propagate and the final failure is oriented at $45^{\circ}$. For the other impacted samples (from $3 \mathrm{~J}$ to $9 \mathrm{~J}$ ), the final failure is almost instantaneous, contrary to what observed with a clean sample which presents a progressive failure. In comparison to the laminate $C_{0} C_{0}$, the curves for the $C_{45} C_{45}$ are first linear and then non-linear. This is due to the pseudo-plastic behaviour of the carbon woven oriented at 
$\pm 45^{\circ}$. Indeed, for in plane-shear, the laminate behaviour is governed by the resin. For epoxy matrix based laminates, the non-linear stage corresponds to a stage of pseudo-hardening, for which anelastic strains emerge and grow, and matrix damaging with the occurrence of resin crackings.

This behaviour explains why the residual normalized tensile strength is lower in comparison to $C_{0} C_{0}$ (Figure 9). In fact, in the non-linear part, the laod increases slower than in the linear part.

For the laminate $C_{45} C_{45}$, the results provided by the digital image processing show that the post-impact behaviour concerning the damage propagation is different compared to the laminate $C_{0} C_{0}$. The first damage propagation starts for a crosshead displacement of $1.6 \mathrm{~mm}$ (Figure 15b). The propagation initiates at each tip of the initial fibres breaks and follows a direction of $\pm 45^{\circ}$ (Figure 15c), which corresponds to the edge of the zone damaged after impact, until they merge each other (Figure 15d). Then the behaviour is similar to $C_{0} C_{0}$. An area around the post-impact damage where the strain field $\varepsilon_{y y}$ is high is identified (Figure 15d). The final rupture quickly occurs.

\subsection{3. $C_{45} C_{0}$ samples}

For the laminate $C_{45} C_{0}$, the same observation than $C_{0} C_{0}$ can be done for the $1 \mathrm{~J}$ case : it is the same behaviour as a clean sample (Figure 16). The post-impact damage is to small to propagate. For the other impact energies, the propagation direction of the damage is between $0^{\circ}$ and $45^{\circ}$ (Figure 16). It shows that the orientation of the plies has an influence on the propagation mechanisms. Nevertheless, the curves (presented on the Figure 17) show that the stiffness of the laminate is predominantly due to the carbon ply $C_{0}$. In fact, the curves are linear and there is no indication of pseudo-plasticity. Furthermore, for example on the $6.25 \mathrm{~J}$ curve, the first break of fibre, which appears for a crosshead displacement of $1.55 \mathrm{~mm}$ and which is noticeable through a slight decrease of the load (just before the final break), occurs in the ply $C_{0}$. So the final break of the laminate is handled by the breakage of the fibres oriented at $0^{\circ}$.

Moreover, during the tensile test, the strain field $\epsilon_{y y}$ in the upper ply $C_{45}$ (Figure 18a) is more similar to what observed for $C_{0} C_{0}$ (Figure 18b) than for $C_{45} C_{45}$ (Figure 18c) at the same displacement. The elongation of the ply $C_{45}$ is managed by the elongation of the ply $C_{0}$. 


\subsection{4. $G_{0} G_{0}$ samples}

The Figure 19 shows the fracture surfaces obtained after the quasi-static tensile tests for each energy of impact and the Figures 20 regroups the corresponding curves. Except for the sample impacted with an energy of $4 \mathrm{~J}$, all the fracture surfaces are the same whatever the energy of impact used : the final break of the sample is horizontal and the two plies break at the same time (Figure 19). Concerning the $4 \mathrm{~J}$ case, for which the is no visible damage after impact (Figure 5), the fracture surface is similar to those of a clean (non-impacted) sample (Figure 19). Nevertheless, Figure 20 shows that the failure occurs for a load $25 \%$ lower than for the clean sample.

The analysis of the damage propagation is identical as for $C_{0} C_{0}$. Indeed, there is an area around the post-impact damage where the strain field $\varepsilon_{y y}$ is high (Figure 21a). It correspond to the loading of the fibres. Areas where the strain $\varepsilon_{x y}$ is not negligible can also be noticed (Figure 21b). They are areas where the resin is loaded. However, the break of the laminate is governed by the fibres breaks.

\subsubsection{Comparison}

Whatever the monomaterial configuration studied, the damage propagation during the post-impact tensile simulation is always governed by fibres breakages and the impacted sample behaves as a non-impacted one when as long as the impact does not produce fibres breakages in the two plies $(1 \mathrm{~J}$ for $C_{0} C_{0} \& C_{45} C_{0}, 2.25 \mathrm{~J}$ for $C_{45} C_{45}$ and $4 \mathrm{~J}$ for $\left.G_{0} G_{0}\right)$. When the two plies of the laminate are identical, the post-impact damage propagation is mainly horizontal $\left(C_{0} C_{0}, C_{45} C_{45}\right.$ and $\left.G_{0} G_{0}\right)$, even if the final break of the laminate occurs much later for $C_{45} C_{45}$ due to its pseudo-plastic behaviour (visible on the load curves with a non-linear part). For $C_{45} C_{0}$, the behaviour is governed by the ply $C_{0}$, the curves being linear and the first fibres breakages initiating in this ply, but the post-impact damage propagation is influenced by each single ply with a propagation between $0^{\circ}$ and $45^{\circ}$.

\subsection{Hybrid samples}

\subsection{1. $G_{0} C_{45} C_{45}$ samples}

Figure 22 shows the fracture surfaces obtained after the quasi-static tensile test for each energy of impact and the Figure 23 represents the corresponding curves. The fracture surfaces are identical for all the energies tested. The post-impact damage propagates and leads to a final break of 
sample oriented at $\pm 45^{\circ}$. The curves are not linear. It is due to the pseudoplastic behaviour of the two plies of carbon woven at $\pm 45^{\circ}$. The damage propagates in three steps. First the break at $\pm 45^{\circ}$ of the glass ply and the resin cracking at $\pm 45^{\circ}$ of the carbon plies is noticed. It corresponds to the first drop of load. Then the stress is recovered by the two carbon plies oriented at $\pm 45^{\circ}$. It corresponds to the part for which the load increases slowly. Finally, the sample breaks with the failure at $\pm 45^{\circ}$ of the two carbon plies which corresponds to the last drop of load.

For the sample impacted at an energy of $1 \mathrm{~J}$, its post-impact behaviour is similar to those of a non-impacted sample. The post-impact damage is too small and does not propagate.

Digital Image Correlation results are analyzed for the sample impacted at $4 \mathrm{~J}$ in order to identify the mechanisms involved in the damage propagation. A comparison between the strain field in the tensile direction $\varepsilon_{y y}$ in the glass ply of the configuration $G_{0} C_{45} C_{45}$ (Figure 24a) and the strain field $\varepsilon_{y y}$ in the upper ply of $C_{45} C_{45}$ (Figure 24b) and $G_{0} G_{0}$ (Figure 24c) shows that the strain field in the ply $G_{0}$ is similar to those of the upper ply of $C_{45} C_{45}$ and different of the upper ply of $G_{0} G_{0}$. Thus, in this laminate, the two carbon plies at $\pm 45^{\circ}$ manage the deformation of the upper ply $G_{0}$.

When the load increases and when the break of fibres initiates, areas of compressive strains transversal to the direction of the load are observed (Figure 25). The fibres of the glass ply are compressed due to the Poisson's effect of the two plies of carbon at $\pm 45^{\circ}$. As a consequence, the glass fibres break in compression along a line oriented at $\pm 45^{\circ}$ (Figure 26a). Finally, a concentration of strains appear in the carbon plies in the zone of breakage of the glass ply (Figure 26b). It leads to a progressive failure of the carbon plies on a strip oriented at $\pm 45^{\circ}$. The final rupture is due to the breakage of the carbon fibres.

\subsection{2. $G_{0} C_{45} C_{0}$ samples}

Figure 27 shows the fracture surfaces obtained after the quasi-static tensile test for each energy of impact and the Figure 28 represents the corresponding curves. Two propagations of the post-impact damage are visible on the Figure 27. For the $1 \mathrm{~J}$ and the $2.25 \mathrm{~J}$ impacted samples, the propagation is horizontal alhtought for the $4 \mathrm{~J}$ to the $16 \mathrm{~J}$ impacted samples, the propagation starts at $\pm 45^{\circ}$ and then continues horizontally.

For the $1 \mathrm{~J}$ and $2.25 \mathrm{~J}$ cases, low damage is observed in the glass ply after impact. As a consequence, the strain field $\varepsilon_{y y}$ in the glass ply near the impact 
zone is smaller than what observed for the $G_{0} C_{45} C_{45}$ sample ((Figure 29). The glass fibres are not loaded enough to propagate the glass ply damage. Figure 30 compares the strain field $\varepsilon_{y y}$ in the lower carbon ply of $G_{0} C_{45} C_{0}$ samples and $C_{45} C_{0}$ samples just before the final break. The shapes and values are similar. The fibres oriented at $0^{\circ}$ are mainly loaded and their breakage manage the horizontal final rupture of the sample.

For the samples impacted above $4 \mathrm{~J}$, fibre breakages in the glass ply are observed after impact. Thus, during the post-impact tensile tests, the damage starts to propagate in the glass ply. In the first stage of the propagation the strain field in the glass ply is similar to that observed in the $G_{0} C_{45} C_{45}$ samples : the damage starts to propagate at $\pm 45^{\circ}$ because it is managed by the carbon ply oriented at $\pm 45^{\circ}$ (Figure 31). However, when the failure

of the glass ply grows, the loads are carried by the $0^{\circ}$ carbon layer. The mechanisms leading to the failure of the sample change : the carbon fibres oriented at $0^{\circ}$ are mainly loaded. Their breakage leads to a final horizontal global failure of the specimen. Indeed, Figure 32 shows that the strain field in the bottom plies of $G_{0} C_{45} C_{0}$ and $C_{45} C_{0}$ samples are the same just before the final break.

\section{Conclusion}

The post-impact damage propagation in thin hybrid carbon-glass/epoxy woven composite laminates under tensile loading has been investigated in this article. Besides the study of the initial damage through the variation of the impact energy, a precise analyze of the damage propagation scenario has been carried out. This analyze is based on the study of the behaviour of monomaterial laminates and on the observation of the strain fields given by Digital Image Correlation. From this study, two main significant results can be highlighted.

First, the hybridization of carbon woven laminates with a ply of glass woven fabric changes significantly the damage propagation scenario. Indeed, if the impact generates fibres breakages, for $C_{0} C_{0}, C_{45} C_{45}$ and $G_{0} G_{0}$, the sample breaks horizontally althought for $C_{45} C_{0}$, the sample breaks between $0^{\circ}$ and $\pm 45^{\circ}$. But, for $G_{0} C_{45} C_{45}$, the laminate breaks at $\pm 45^{\circ}$ in three steps and for $G_{0} C_{45} C_{0}$, the damage propagation is mainly horizontal. In the $G_{0} C_{45} C_{0}$ case, the hybridization has a beneficial effect. The final tensile break of the impacted hybrid laminate occurs for higher load and elongation than that of $C_{45} C_{0}$. For $G_{0} C_{45} C_{45}$, the conclusion depends on the desired effect. 
The addition of the glass ply also leads to an increase of the maximum load during the tensile test, but the break elongation decreases. This consequence of the hybridization is visible for the sample of which the damage does not propagate. The addition of the glass ply $G_{0}$ reduces the influence of the pseudo-plastic behaviour of the two carbon plies $C_{45} C_{45}$, with a non-linearity of the load curves less pronounced in comparison to $C_{45} C_{45}$.

The second significant results is that the damage propagation scenario is the result of an interaction between the post-impact damage size, the stacking sequence and the contribution of each ply of the laminate. In fact, two different behaviour are observed depending on the hybrid laminate. The damage propagation scenarios are completely different. For $G_{0} C_{45} C_{0}$, the propagation depends also on the energy of impact. For lower impact energies, the fracture surface is horizontal while for higher impact energies, the propagation begins at $\pm 45^{\circ}$ and finishes horizontally.

This study has also confirmed some litterature obervations for monomaterial laminates and has shown that they can be applied to hybrid laminates : the propagation of the damage is always governed by fibres breakages and the residual strength always decreases in three steps with the impact energy. First the decrease is very low, then it strongly grows and finally it becames constant. The start of the second and the third steps seems to correspond to the energy respectively required to create fibre breakage and completely perforate the laminate.

The second part of this article will be focused on the modelling of the tests studied in this part. First, numerical developements, based on the experimental observations made in this part, will be presented. Then, the modelling will be validated through a numerical/experimental comparison. Results will be used in order to explain the influence of the impact energy on the damage propagation scenario in a laminate of configuration $G_{0} C_{45} C_{0}$. 


\section{References}

[1] G. Caprino, Residual strength prediction of impacted cfrp laminates, Journal of Composite Materials 18 (6) (1984) 508-518.

[2] W. Cantwell, J. Morton, An assessment of the residual strength of an impact-damaged carbon fibre reinforced epoxy, Composite Structures 14 (4) (1990) $303-317$.

[3] M. Richardson, M. Wisheart, Review of low-velocity impact properties of composite materials, Composites Part A: Applied Science and Manufacturing 27 (12) (1996) 1123 - 1131.

[4] A. Mosallam, J. Slenk, J. Kreiner, Assessment of residual tensile strength of carbon/epoxy composites subjected to low-energy impact, Journal of Aerospace Engineering 21 (4) (2008) 249-258.

[5] S.-X. Wang, L.-Z. Wu, L. Ma, Low-velocity impact and residual tensile strength analysis to carbon fiber composite laminates, Materials \& Design 31 (1) (2010) 118 - 125.

[6] V. Balasubramani, S. Boopathy, Prediction of residual tensile strength of laminated composite plates after low velocity impact, Journal of Engineering and Applied Sciences 9 (2014) 320-325.

[7] J.-K. Kim, M.-L. Sham, Impact and delamination failure of woven-fabric composites, Composites Science and Technology 60 (5) (2000) 745 - 761.

[8] G. Davies, D. Hitchings, G. Zhou, Impact damage and residual strengths of woven fabric glass/polyester laminates, Composites Part A: Applied Science and Manufacturing 27 (12) (1996) 1147 - 1156.

[9] V. Shim, L. Yang, Characterization of the residual mechanical properties of woven fabric reinforced composites after low-velocity impact, International Journal of Mechanical Sciences 47 (2005) 647-665.

[10] P. Schubel, J.-J. Luo, I. Daniel, Impact and post impact behavior of composite sandwich panels, Composites Part A: Applied Science and Manufacturing 38 (3) (2007) 1051 - 1057. 
[11] A. Aktas, M. Aktas, F. Turan, The effect of stacking sequence on the impact and post-impact behavior of woven/knit fabric glass/epoxy hybrid composites, Composite Structures 103 (2013) 119 - 135.

[12] J.-M. Koo, J.-H. Choi, C.-S. Seok, Prediction of residual strength of cfrp after impact, Composites Part B: Engineering 54 (2013) 28-33.

[13] Investigation of impact residual strength of woven and non-woven composites.

[14] M. Kounain, F. Al-Sulaiman, Z. Khan, Low velocity impact and post impact tensile properties of plain weave woven gfrp composite laminates, International Journal of Engineering and Advanced Technology 5 (2) (2015) 92-99.

[15] S. Mouhoubi, K. Azouaoui, Residual properties of composite plates subjected to impact fatigue, Journal of Composite Materials (2018).

[16] A. Bunsell, B. Harris, Hybrid carbon and glass fibre composites, Composites 5 (4) (1974) 157 - 164.

[17] J. Aveston, J. M. Sillwood, Synergistic fibre strengthening in hybrid composites, Journal of Materials Science 11 (10) (1976) 1877-1883.

[18] J. Summerscales, D. Short, Carbon fibre and glass fibre hybrid reinforced plastics, Composites 9 (3) (1978) 157 - 166.

[19] G. Marom, S. Fischer, F. Tuler, H. Wagner, Hybrid effects in composites: conditions for positive or negative effects versus rule-of-mixtures behaviour, Journal of Materials Science 13 (7) (1978) 1419-1426.

[20] P. W. Manders, M. G. Bader, The strength of hybrid glass/carbon fibre composites, Journal of Materials Science 16 (8) (1981) 2246-2256.

[21] G. Kretsis, A review of the tensile, compressive, flexural and shear properties of hybrid fibre-reinforced plastics, Composites 18 (1) (1987) 13 23.

[22] M. Ikbal, Tensile properties of bidirectional glass-carbon hybrid composites: Part i. (2018). 
[23] B. Harris, A. Bunsell, Impact properties of glass fibre/carbon fibre hybrid composites, Composites 6 (5) (1975) $197-201$.

[24] K. Saka, J. Harding, A simple laminate theory approach to the prediction of the tensile impact strength of woven hybrid composites, Composites 21 (5) (1990) $439-447$.

[25] A. Enfedaque, J. Molina-Aldareguía, F. Gàlvez, C. Gonzàlez, J. LLorca, Effect of glass fiber hybridization on the behavior under impact of woven carbon fiber/epoxy laminates, Journal of Composite Materials 44 (25) (2010) 3051-3068.

[26] M. Hosur, M. Adbullah, S. Jeelani, Studies on the low-velocity impact response of woven hybrid composites, Composite Structures 67 (3) (2005) $253-262$.

[27] K. Imielińska, M. Castaings, R. Wojtyra, J. Haras, E. Le Clezio, B. Hosten, Air-coupled ultrasonic c-scan technique in impact response testing of carbon fibre and hybrid: glass, carbon and kevlar/epoxy composites, Journal of Materials Processing Technology 157-158 (2004) 513 -522 .

[28] J. Gustin, A. Joneson, M. Mahinfalah, J. Stone, Low velocity impact of combination kevlar/carbon fiber sandwich composites, Composite Structures 69 (4) (2005) $396-406$.

[29] M. Sayer, N. Bekta,S, O. Sayman, An experimental investigation on the impact behavior of hybrid composite plates, Composite Structures 92 (5) (2010) $1256-1262$.

[30] B. Jang, L. Chen, C. Wang, H. Lin, R. Zee, Impact resistance and energy absorption mechanisms in hybrid composites, Composites Science and Technology 34 (4) (1989) $305-335$.

[31] C. Wang, B. Jang, J. Panus, B. Valaire, Impact behavior of hybridfiber and hybrid-matrix composites, Journal of Reinforced Plastics and Composites 10 (4) (1991) 356-378.

[32] V. Kowsika, R. Mantena, Static and low-velocity impact response characteristics of pultruded hybrid glass-graphite/epoxy composite beams, Journal of Thermoplastic Composite Materials 12 (2) (1999) 121-132. 
[33] I. De Rosa, M. F., G. Pulci, C. Santulli, F. Sarasini, J. Tirillò, M. Valente, Post-impact mechanical characterisation of glass and basalt woven fabric laminates, Applied Composite Materials - APPL COMPOS MATER 19 (3-4) (2011) 1-16.

[34] S. Nunna, P. Chandra, A. Shrivastava, S.and Jalan, A review on mechanical behavior of natural fiber based hybrid composites, Journal of Reinforced Plastics and Composites 31 (11) (2012) 759-769.

[35] F. Sarasini, J. Tirillò, M. Valente, L. Ferrante, S. Cioffi, S. Iannace, L. Sorrentino, Hybrid composites based on aramid and basalt woven fabrics: Impact damage modes and residual flexural properties, Materials \& Design 49 (2013) 290 - 302.

[36] R. Petrucci, C. Santulli, D. Puglia, E. Nisini, F. Sarasini, J. Tirillò, L. Torre, G. Minak, J. Kenny, Impact and post-impact damage characterisation of hybrid composite laminates based on basalt fibres in combination with flax, hemp and glass fibres manufactured by vacuum infusion, Composites Part B: Engineering 69 (2015) 507 - 515.

[37] H. Liu, B. G. Falzon, W. Tan, Experimental and numerical studies on the impact response of damage-tolerant hybrid unidirectional/woven carbon-fibre reinforced composite laminates, Composites Part B: Engineering 136 (2018) $101-118$.

[38] B. Mahmoud, L. Manseri, A. Rogani, P. Navarro, S. Marguet, J.-F. Ferrero, I. Tawk, Experimental and numerical study of the damage mechanisms in hybrid unidirectional/woven composites under impact loading, Composite Structures 209 (2019) 606 - 615.

[39] N. Naik, R. Ramasimha, H. Arya, P. S.V., N. ShamaRao, Impact response and damage tolerance characteristics of glass-carbon/epoxy hybrid composite plates, Composites Part B: Engineering 32 (7) (2001) $565-574$.

[40] M. Dehkordi, H. Nosraty, M. Shokrieh, G. Minak, D. Ghelli, The influence of hybridization on impact damage behavior and residual compression strength of intraply basalt/nylon hybrid composites, Materials \& Design 43 (2013) $283-290$. 
[41] P. Navarro, Etude de l'impact oblique à haute vitesse sur des structures en sandwich composite : application aux pales d'hélicoptère, Ph.D. thesis, Université Toulouse 3 Paul Sabatier (2010).

[42] J. Aubry, Etude expérimentale et numérique d'impact sur structures : application aux pales d'hélicoptères, Ph.D. thesis, Université Toulouse 3 Paul Sabatier (2013). 


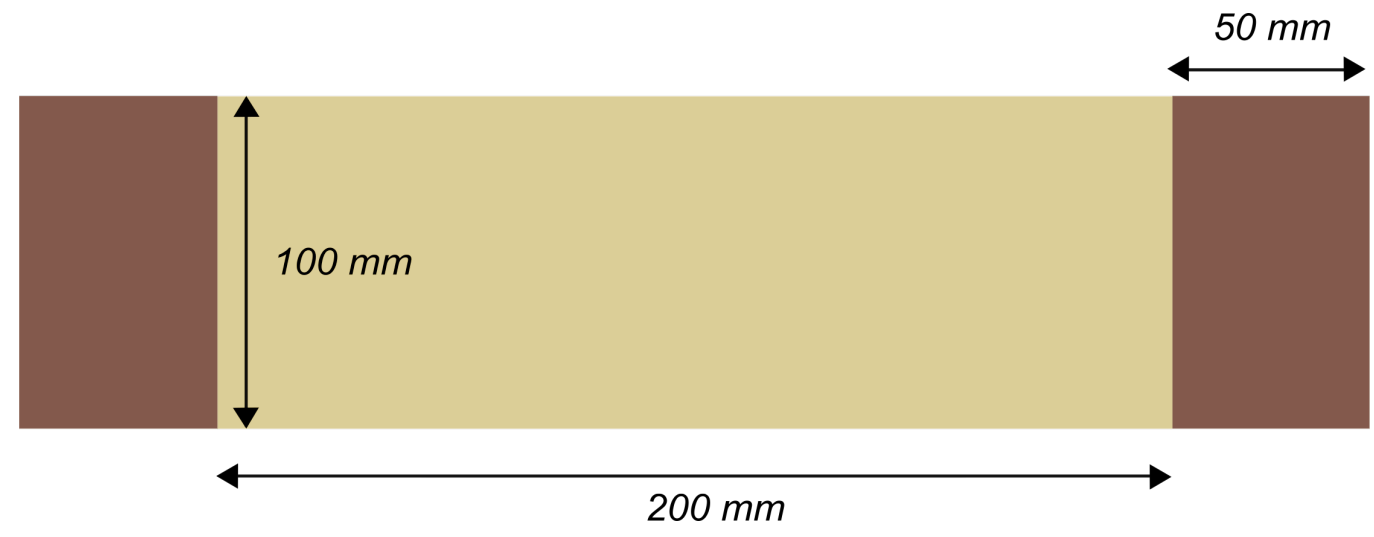

Figure 1: Sample geometry

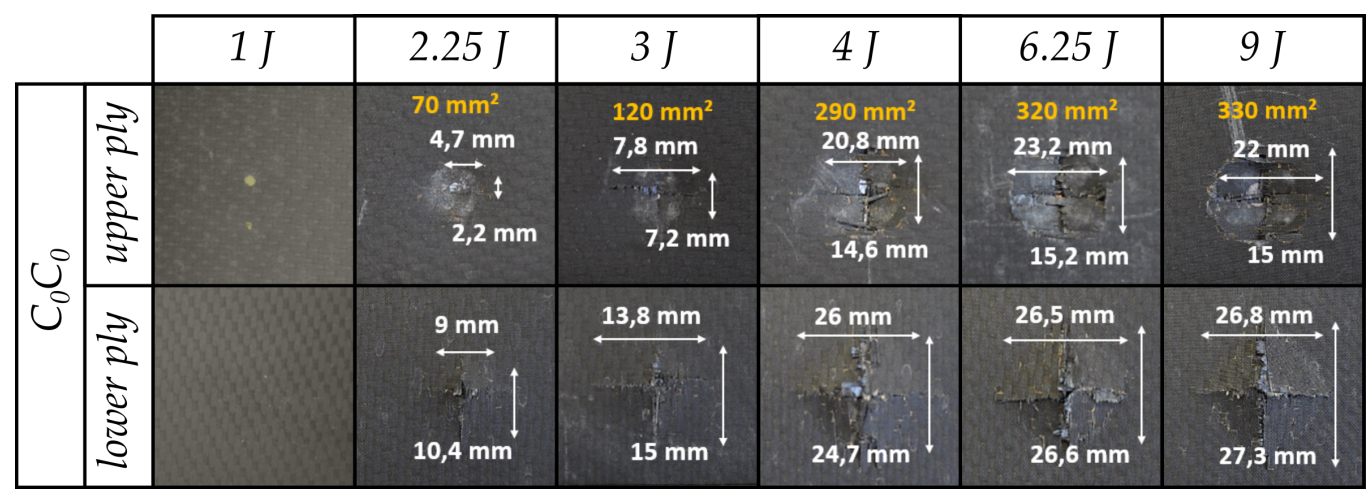

Figure 2: Post-impact fracture surfaces on $C_{0} C_{0}$ samples 


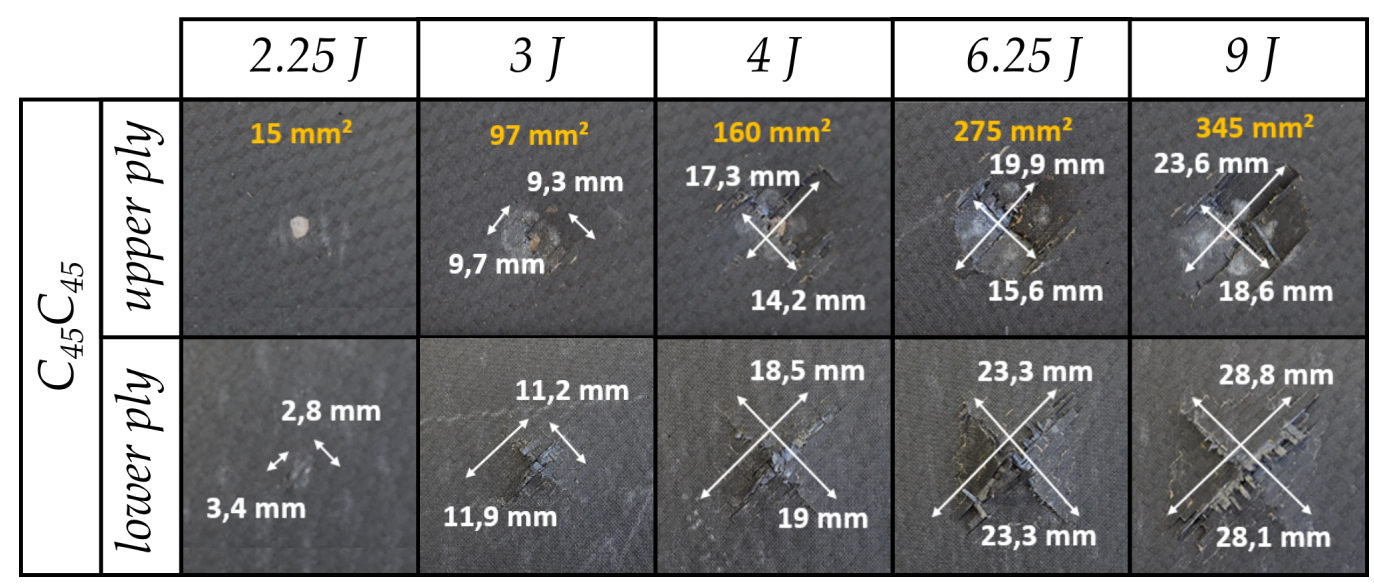

Figure 3: Post-impact fracture surfaces on $C_{45} C_{45}$ samples

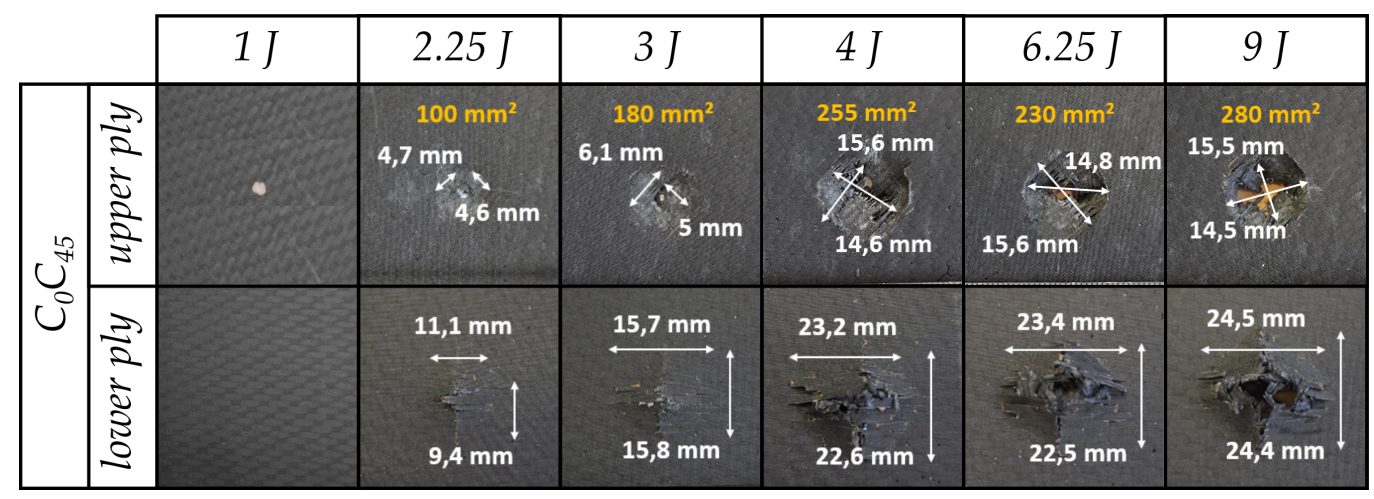

Figure 4: Post-impact fracture surfaces on $C_{45} C_{0}$ samples 


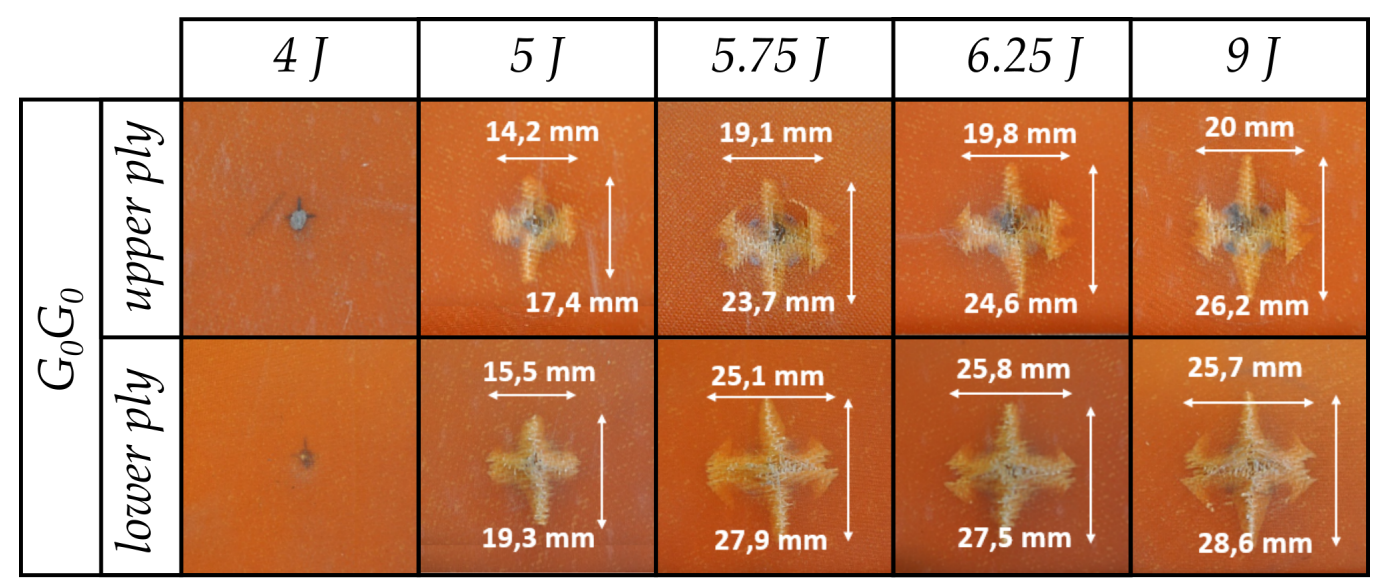

Figure 5: Post-impact fracture surfaces on $G_{0} G_{0}$ samples

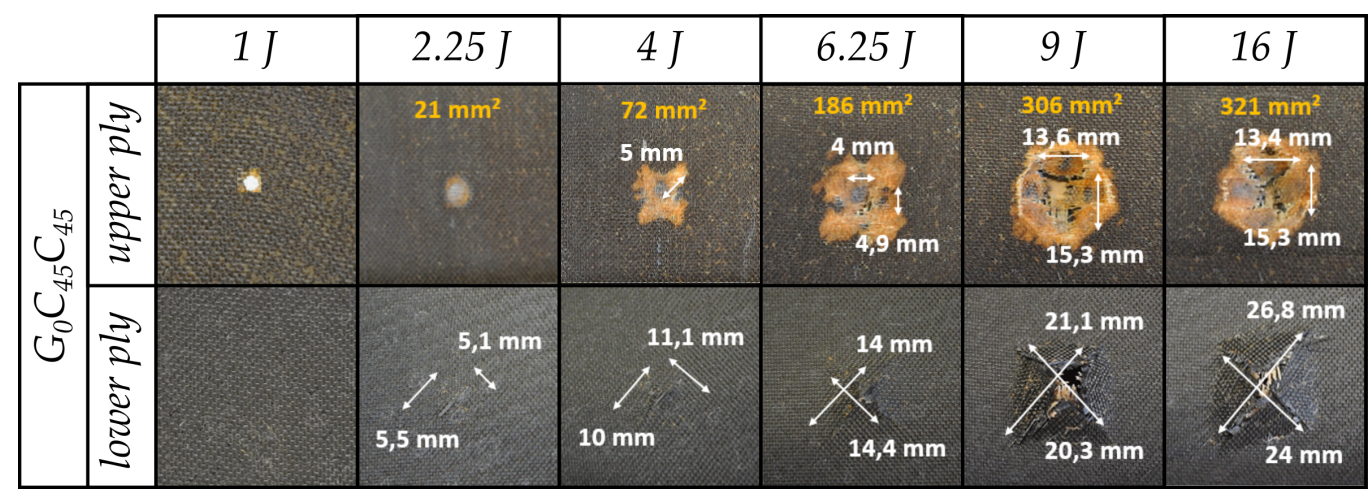

Figure 6: Post-impact fracture surfaces on $G_{0} C_{45} C_{45}$ samples

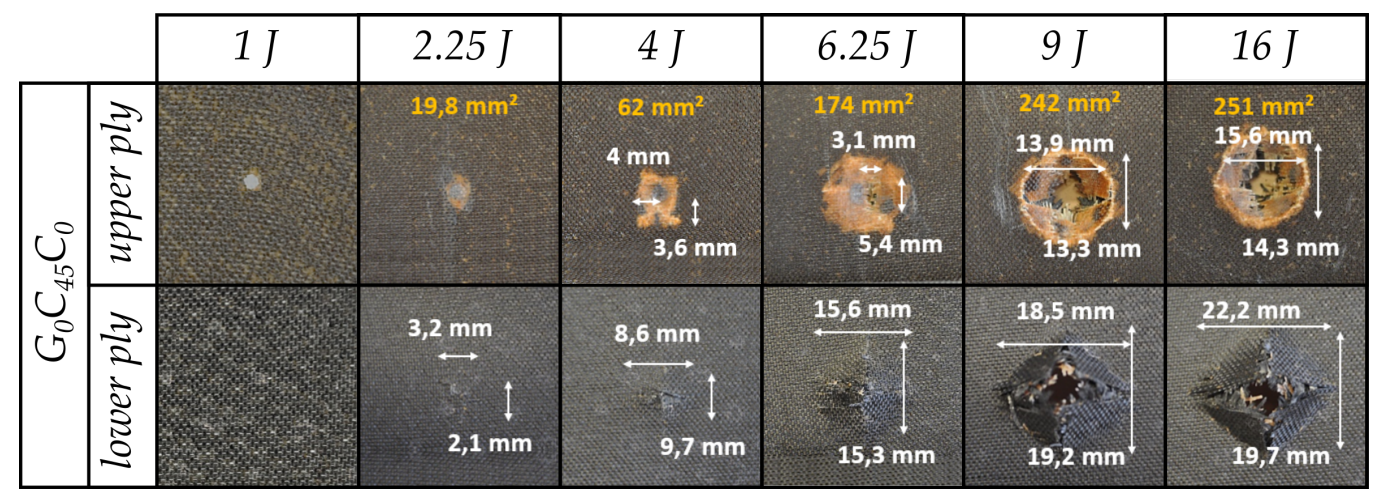

Figure 7: Post-impact fracture surfaces on $G_{0} C_{45} C_{0}$ samples 


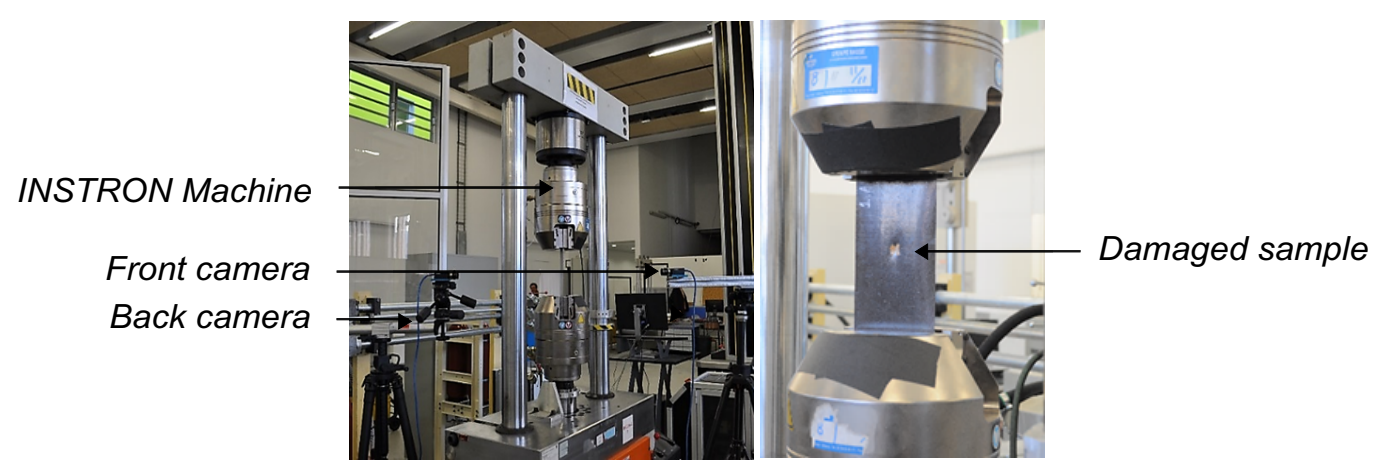

Figure 8: Tensile test on damaged sample 


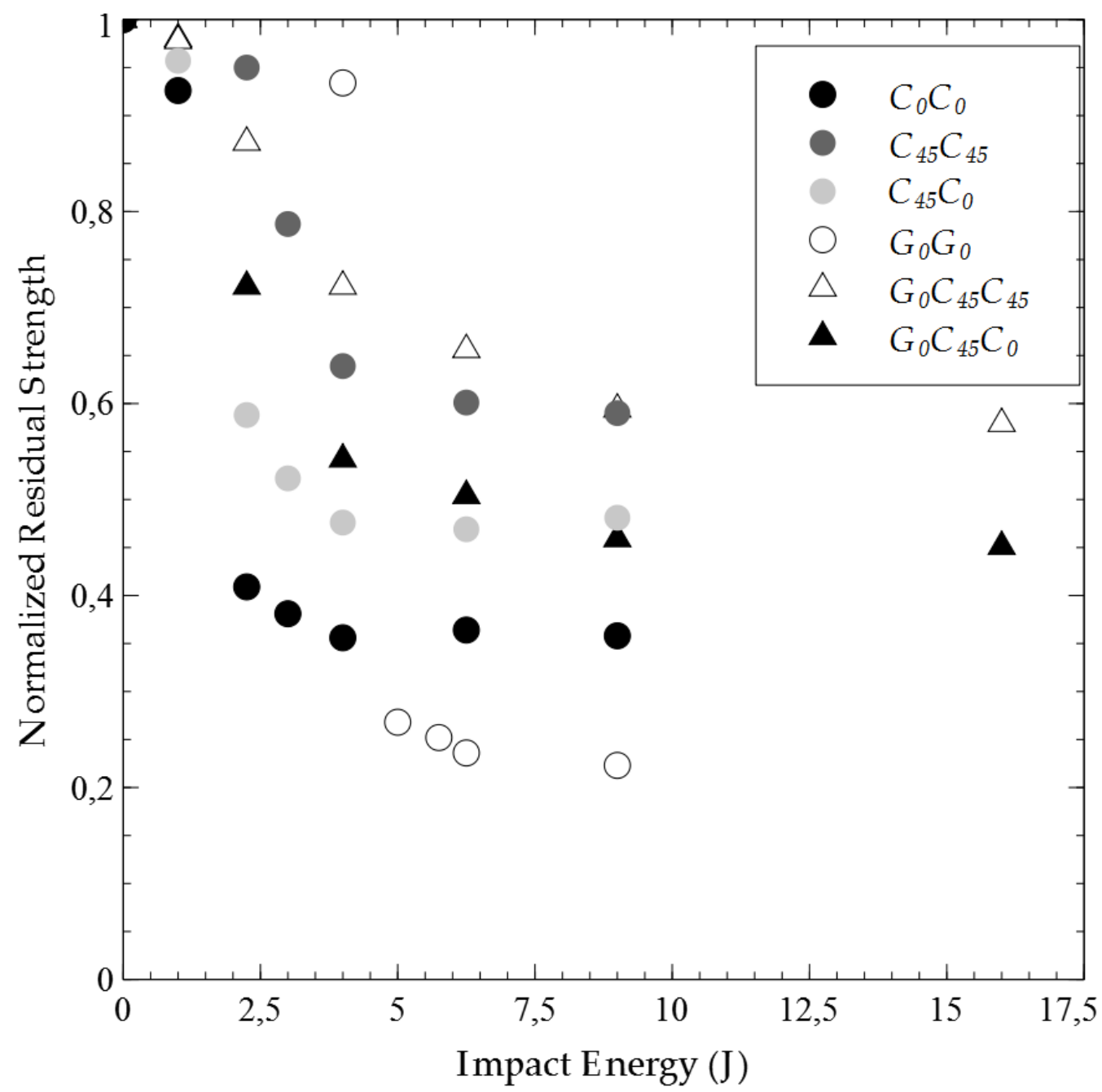

Figure 9: Residual normalized tensile strength versus impact energy for all the configurations 


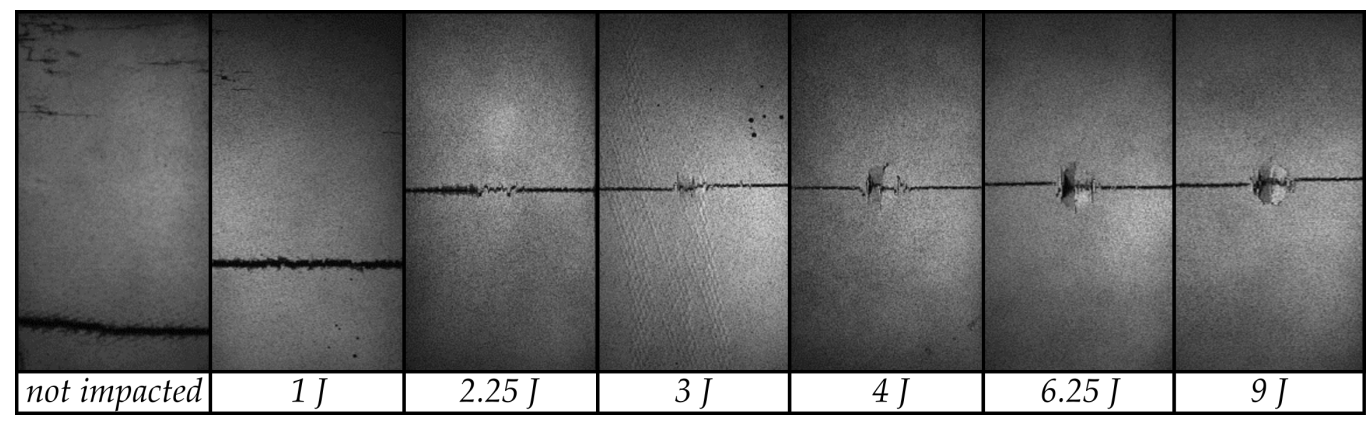

Figure 10: Fracture surfaces after tensile tests on post-impacted $C_{0} C_{0}$ samples 


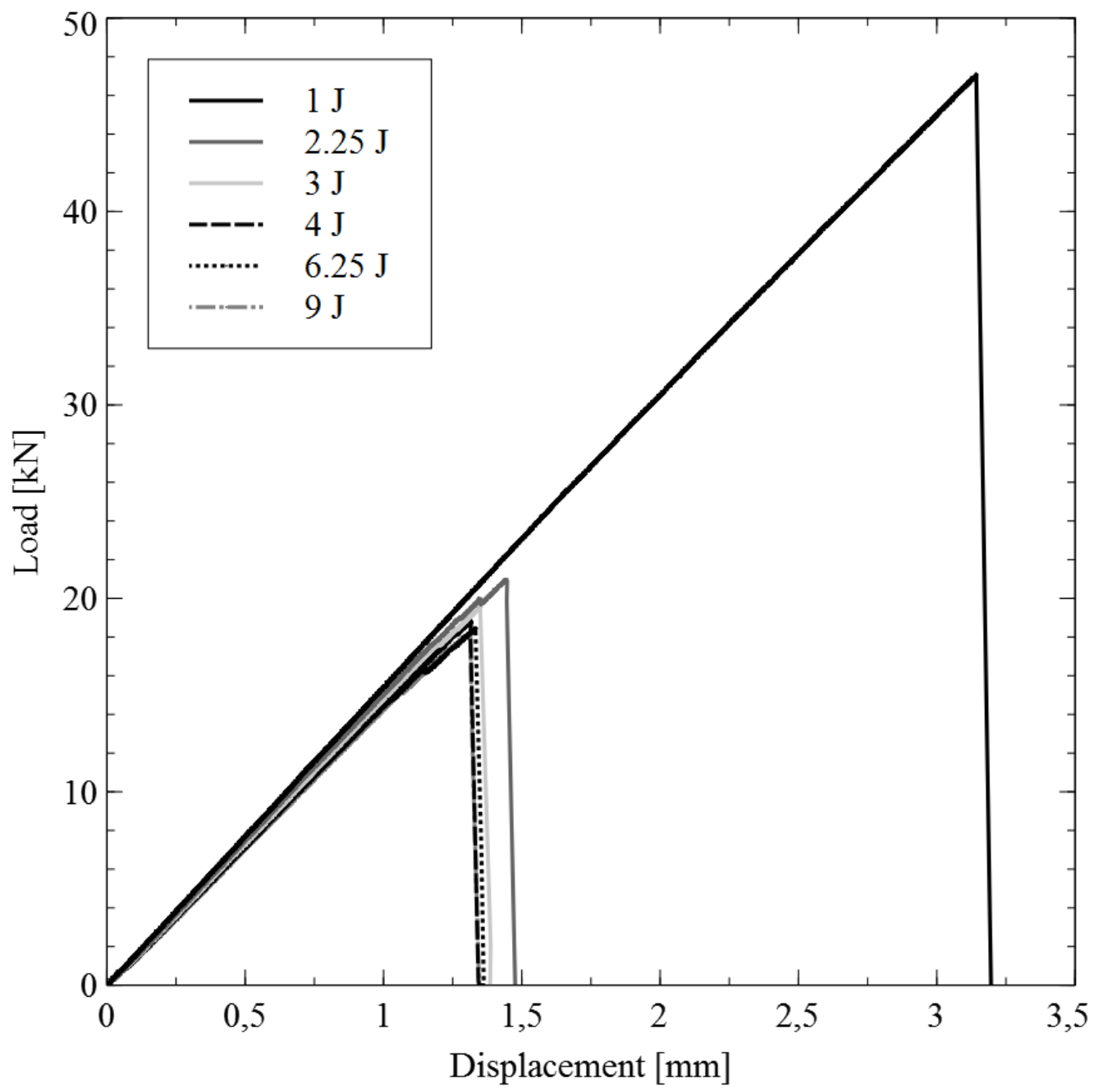

Figure 11: Load - Crosshead displacement curves for post-impact quasi-static tensile tests with different energies for $C_{0} C_{0}$ 

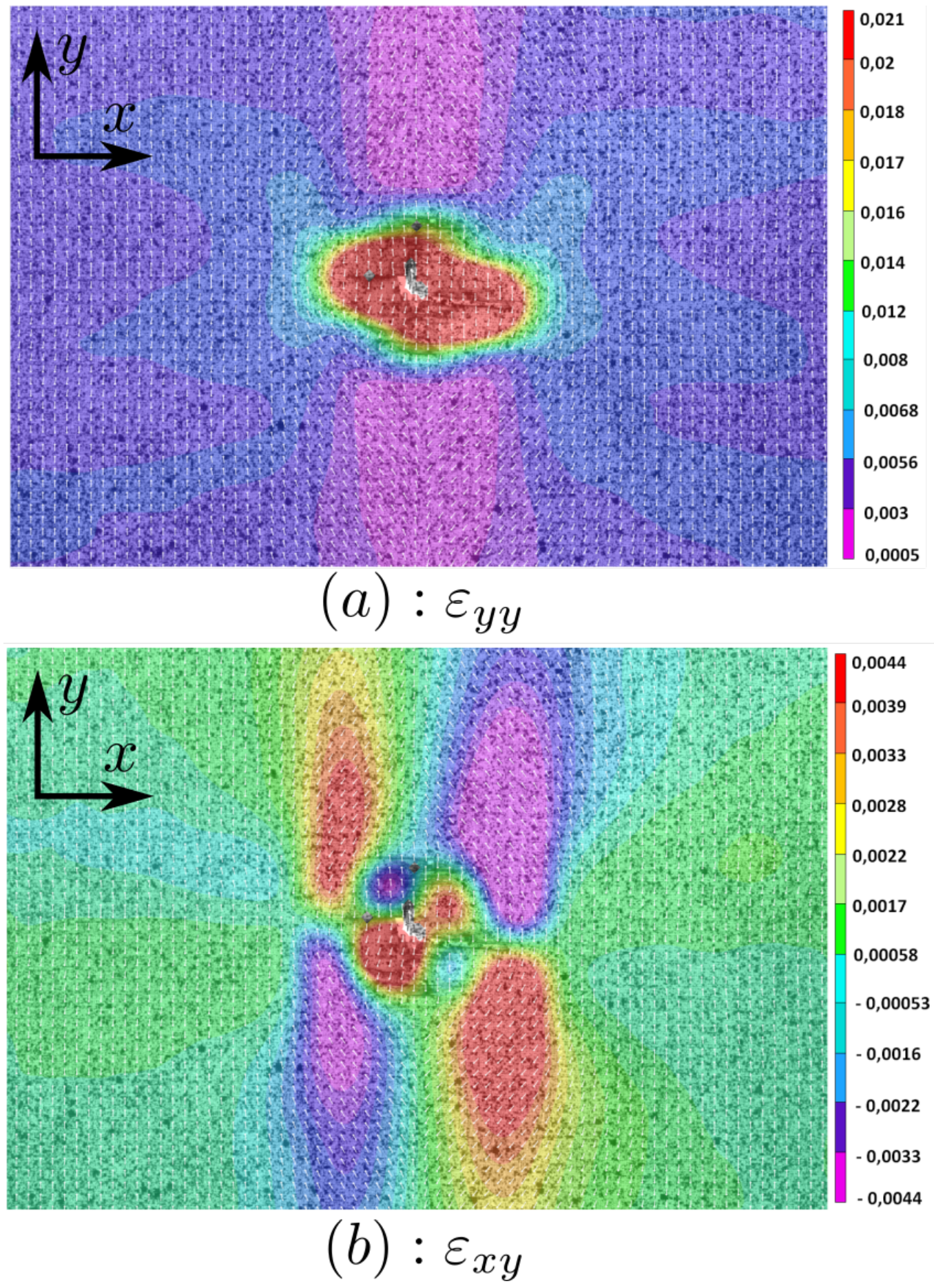

Figure 12: Strain fields from digital image processing for $C_{0} C_{0}$ (identical in the two plies) 


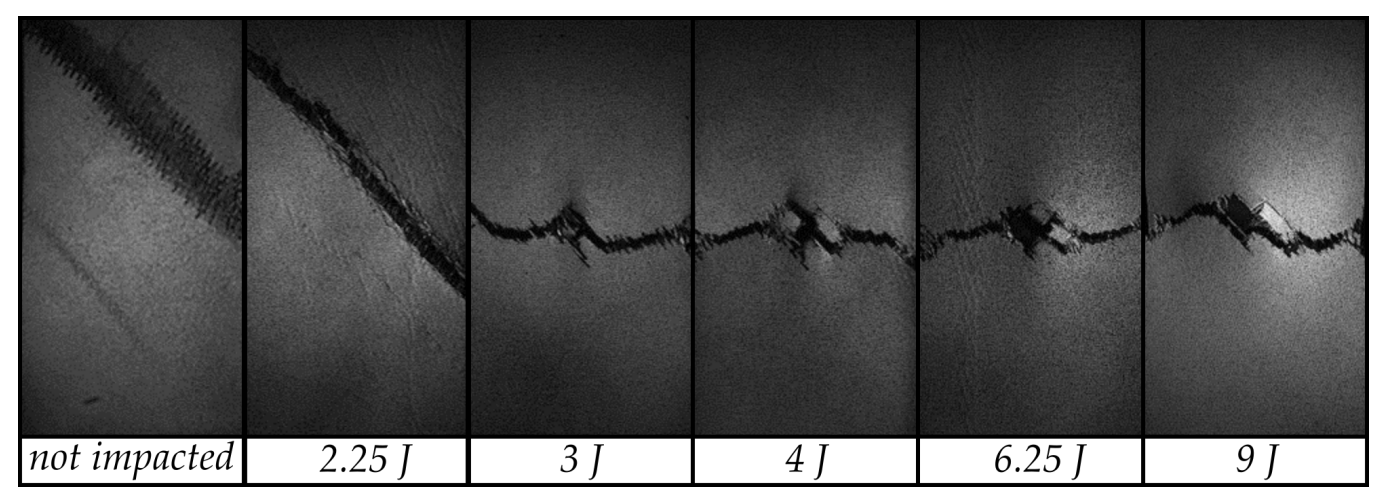

Figure 13: Fracture surfaces for post-impact quasi-static tensile tests of $C_{45} C_{45}$ 


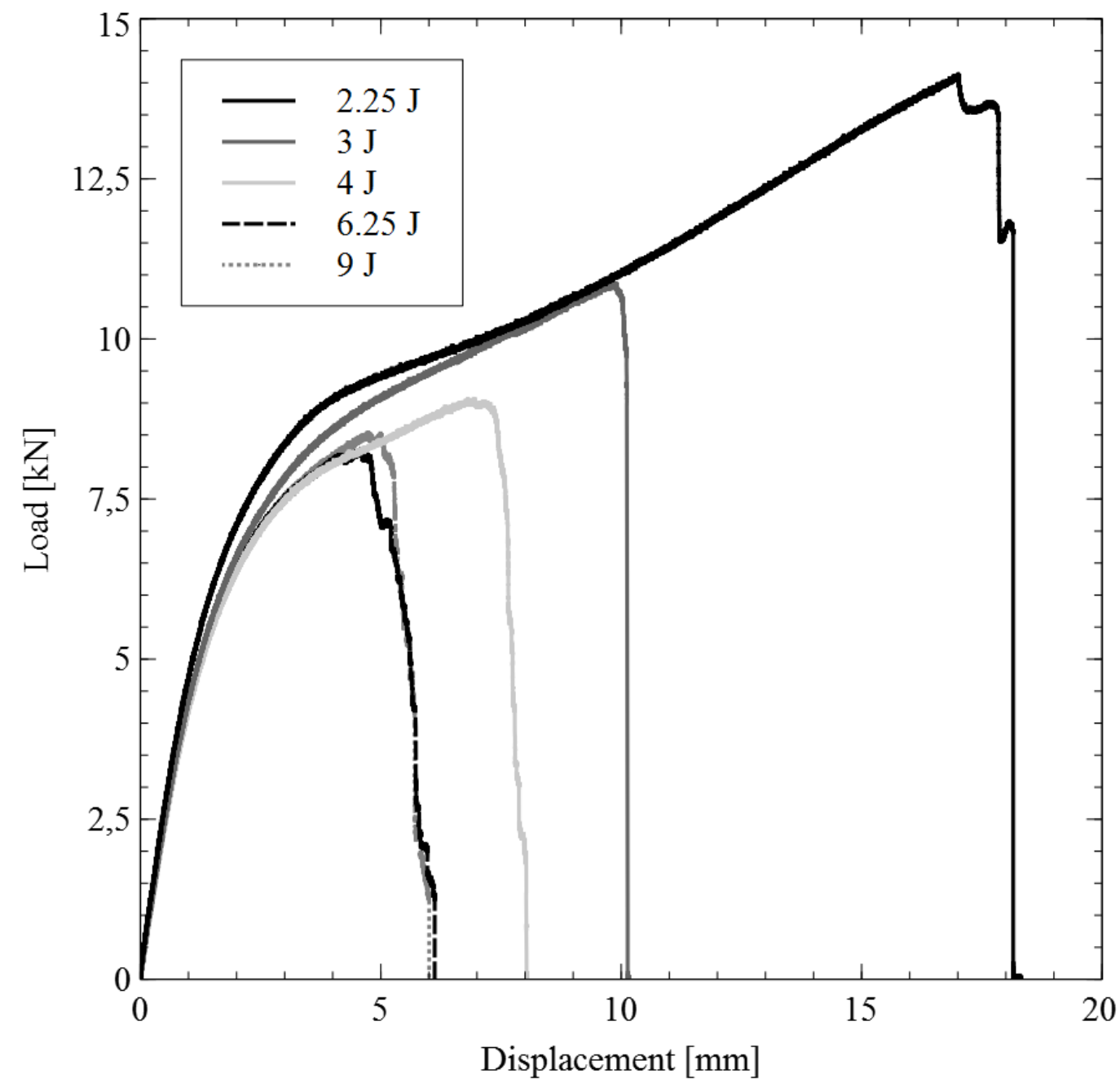

Figure 14: Load - Crosshead displacement curves for post-impact quasi-static tensile tests with different energies for $C_{45} C_{45}$ 


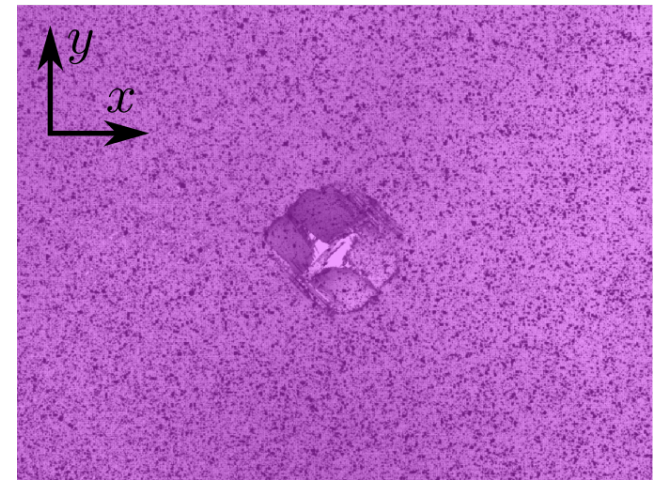

(a) :0mm

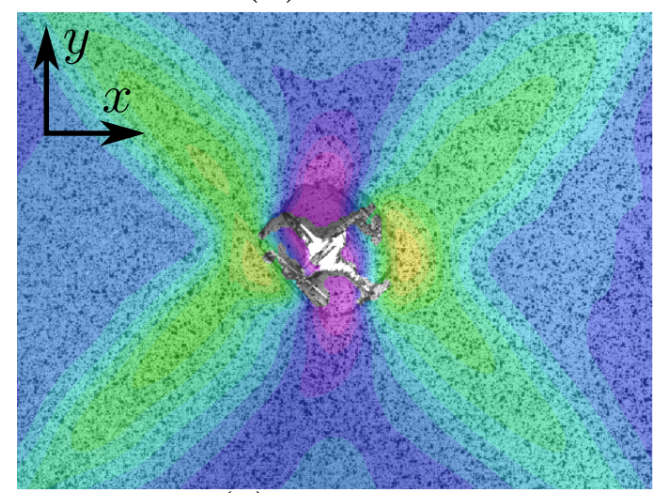

(c) $: 3.5 \mathrm{~mm}$

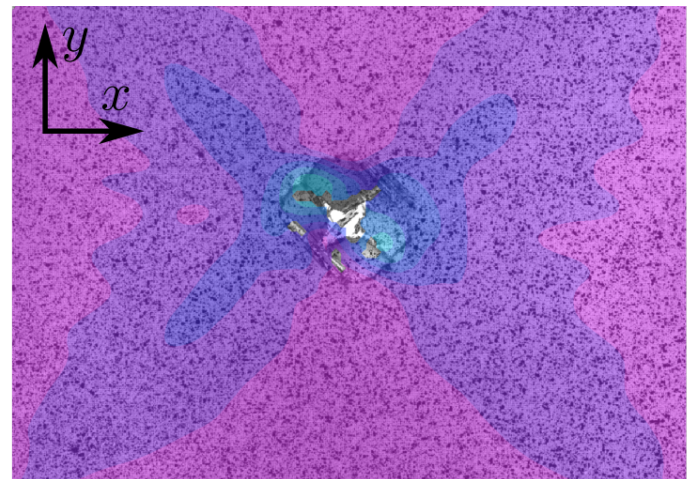

(b) $: 1.6 \mathrm{~mm}$

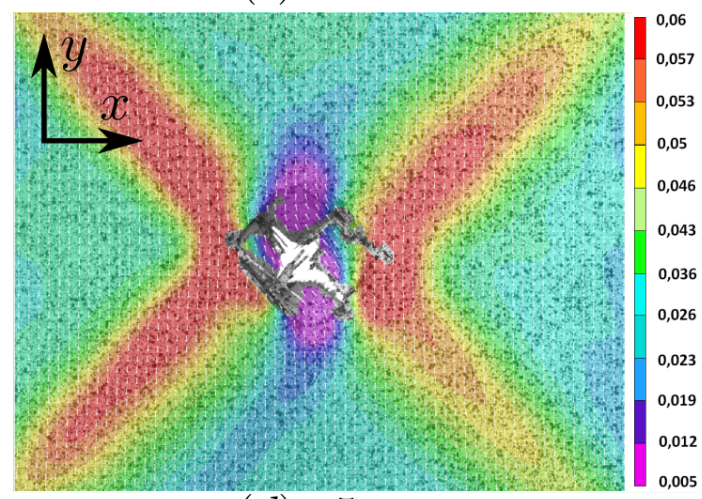

$(d): 5 m m$

Figure 15: Strain field $\epsilon_{y y}$ from DIC for $C_{45} C_{45}$ for a $6.25 \mathrm{~J}$ impacted sample (identical in the two plies)

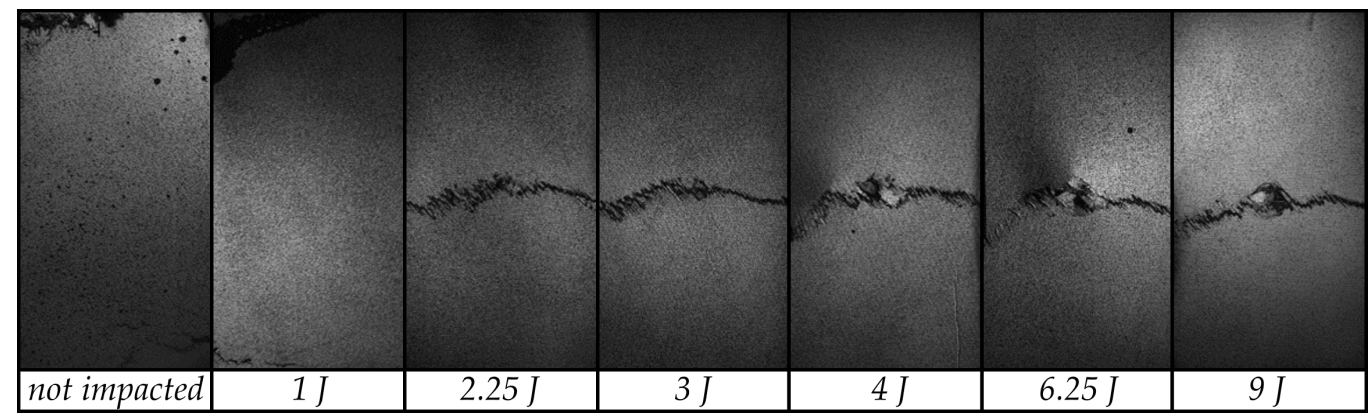

Figure 16: Fracture surfaces for post-impact quasi-static tensile tests of $C_{45} C_{0}$ 


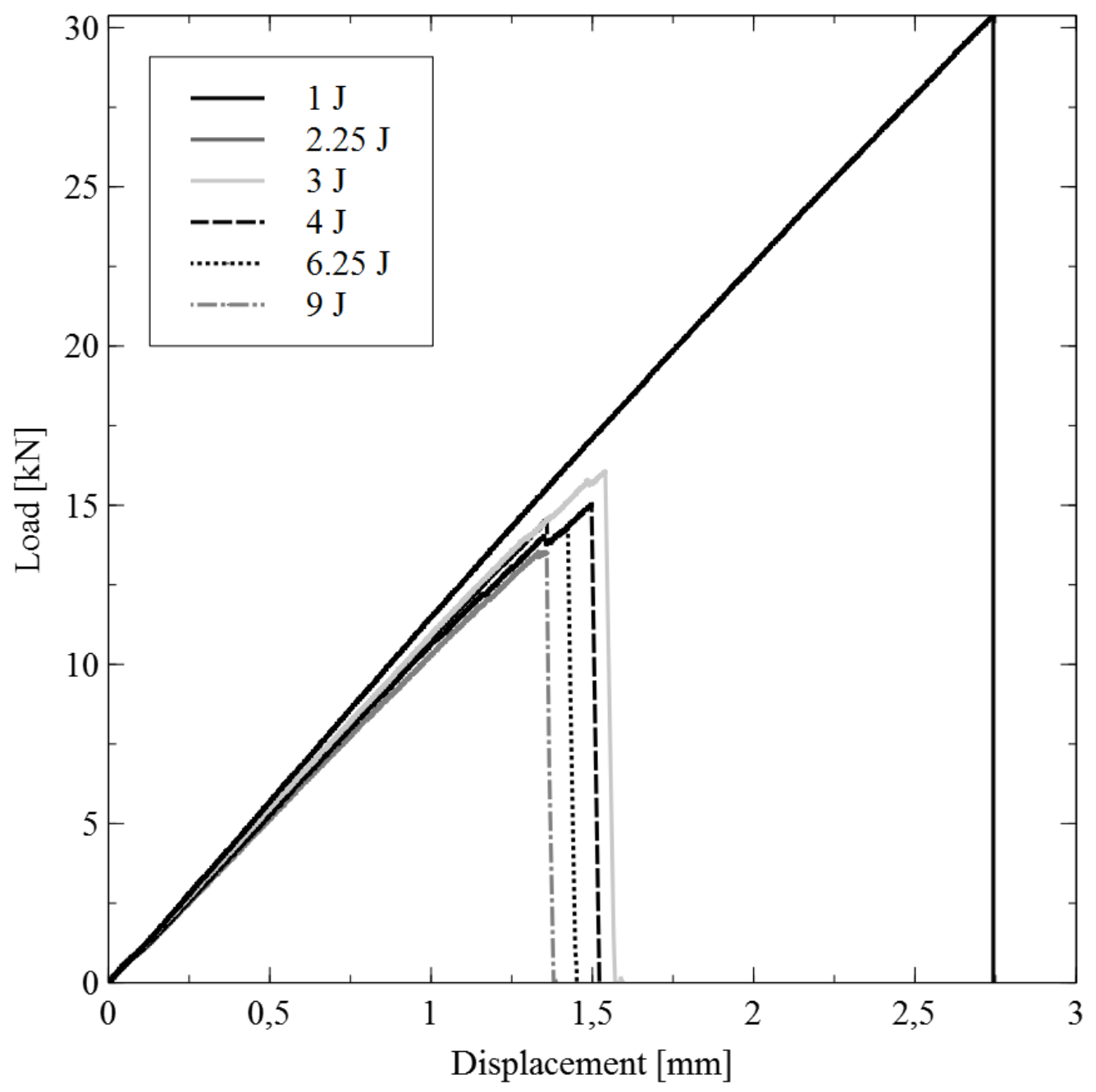

Figure 17: Load - Crosshead displacement curves for post-impact quasi-static tensile tests with different energies for $C_{45} C_{0}$ 


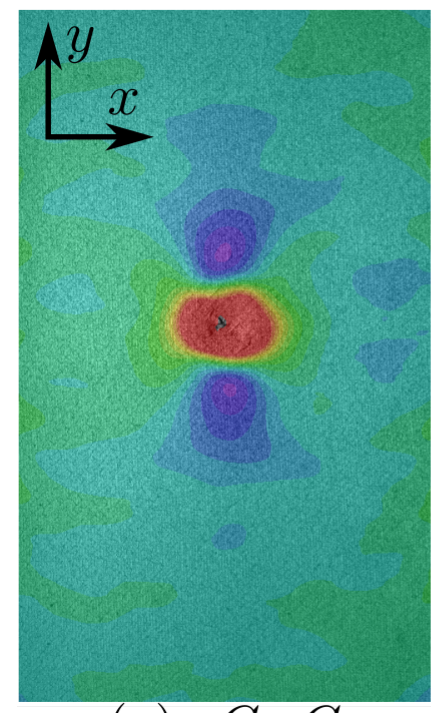

(a) $: C_{45} C_{0}$

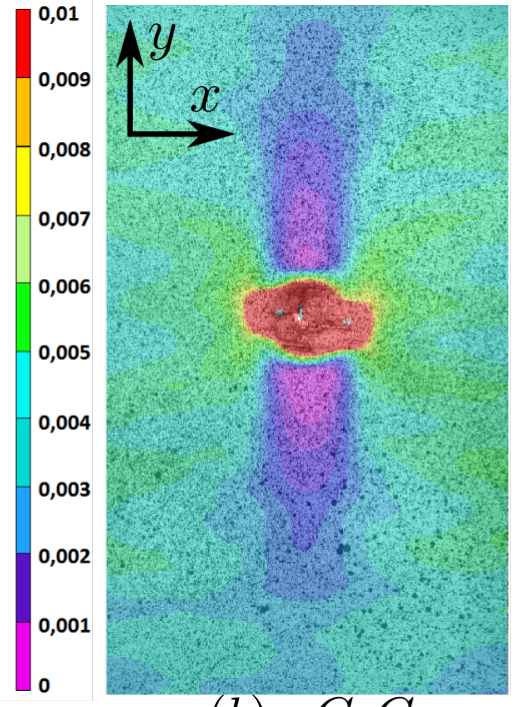

(b) $: C_{0} C_{0}$

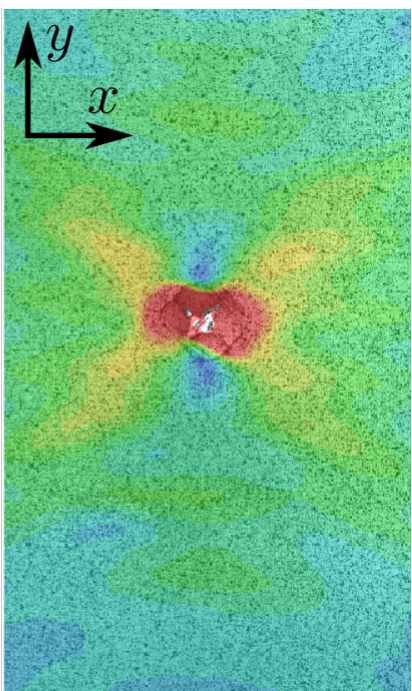

(c) : $C_{45} C_{45}$

Figure 18: Strain field $\epsilon_{y y}$ from digital image processing in the upper ply of $C_{45} C_{0}$ for a crosshead displacement of $1 \mathrm{~mm}$ - Comparison with $C_{0} C_{0}$ and $C_{45} C_{45}$



Figure 19: Fracture surfaces for post-impact quasi-static tensile tests of $G_{0} G_{0}$ (identical in the two plies) 


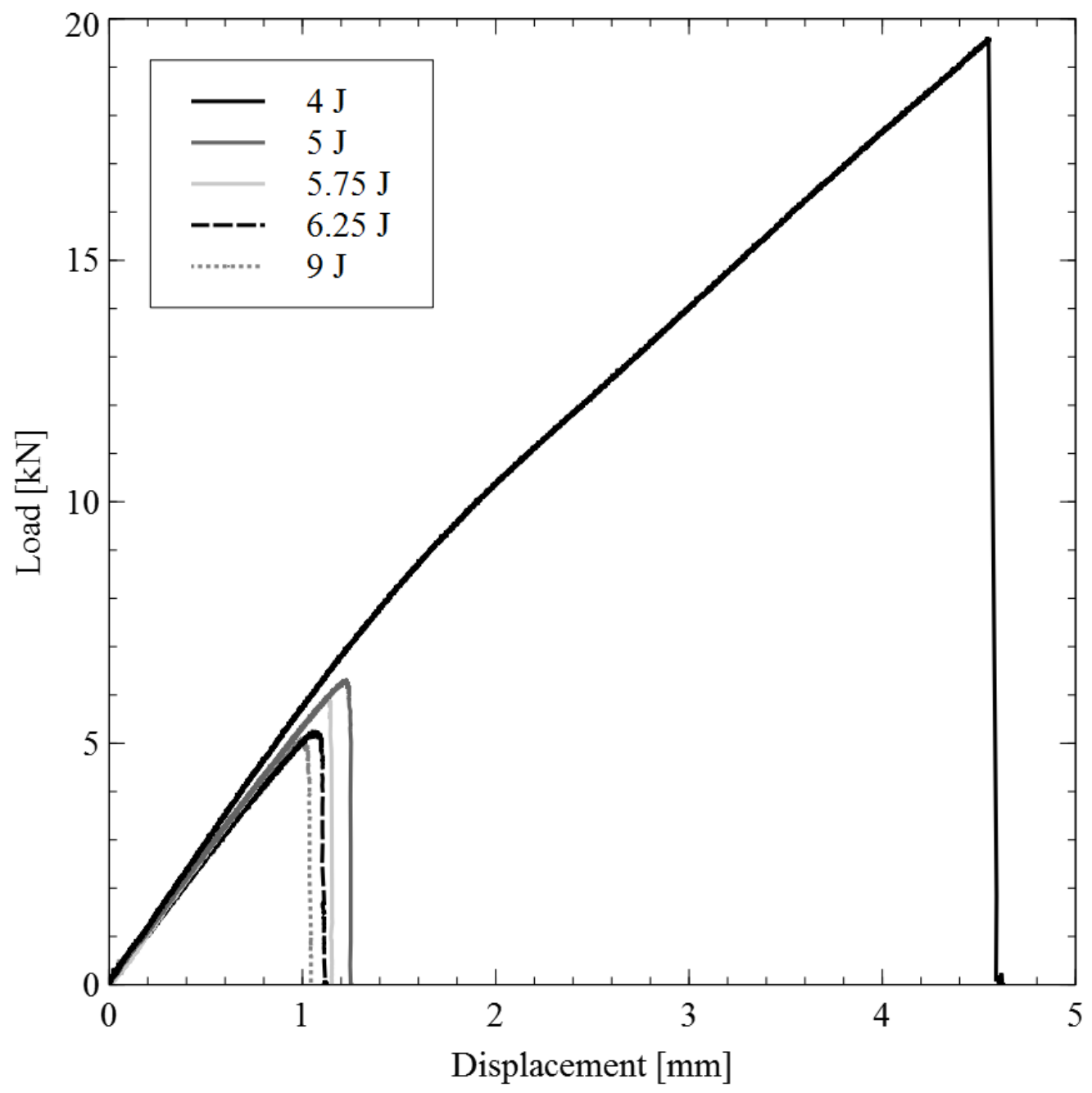

Figure 20: Load - Crosshead displacement curves for post-impact quasi-static tensile tests with different energies for $G_{0} G_{0}$ 

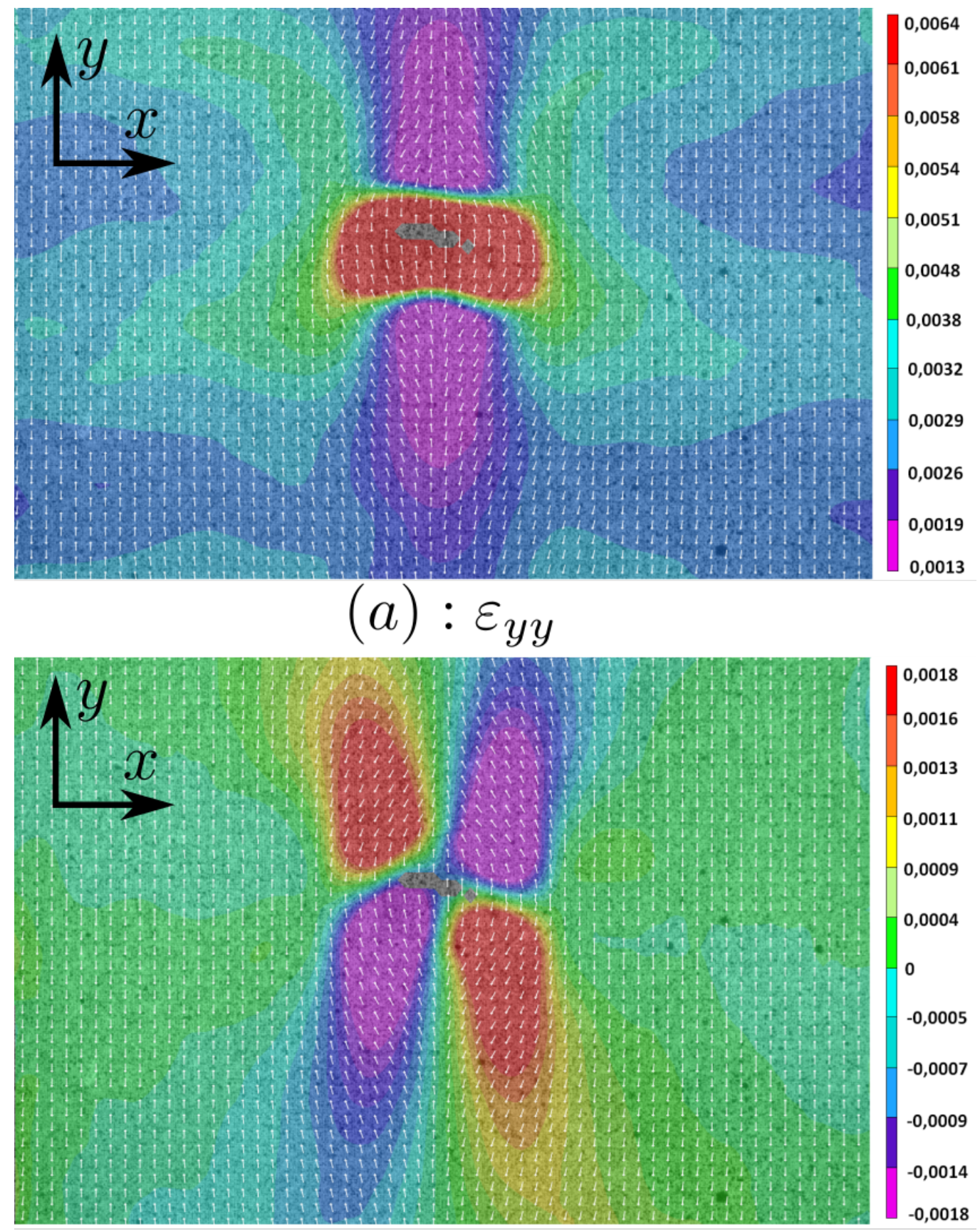

$$
(b): \varepsilon_{x y}
$$

Figure 21: Strain fields from digital image processing for $G_{0} G_{0}$ (identical in the two plies) 




Figure 22: Fracture surfaces for post-impact quasi-static tensile tests of $G_{0} C_{45} C_{45}$ 


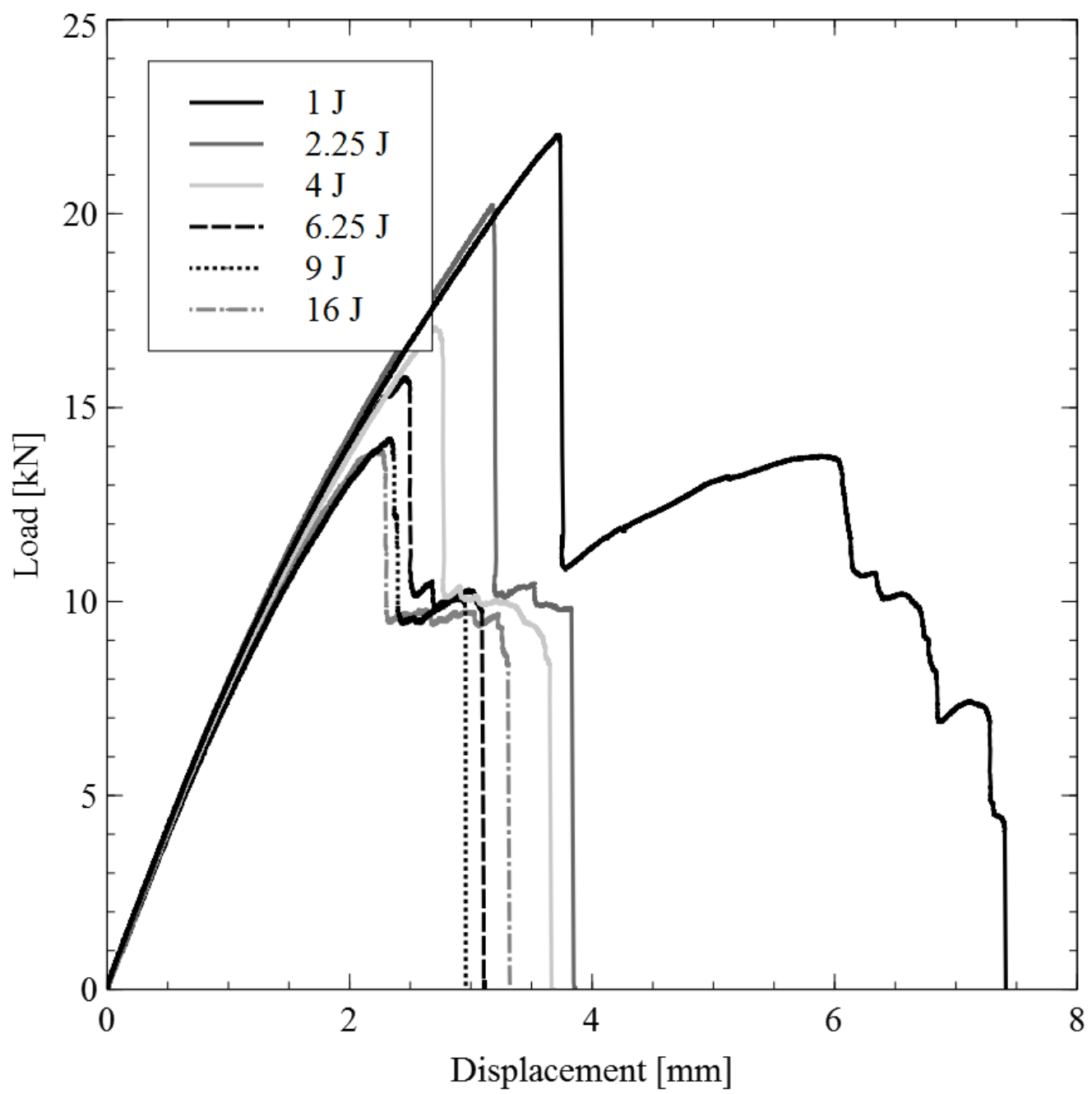

Figure 23: Load - Crosshead displacement curves for post-impact quasi-static tensile tests of $G_{0} C_{45} C_{45}$ 

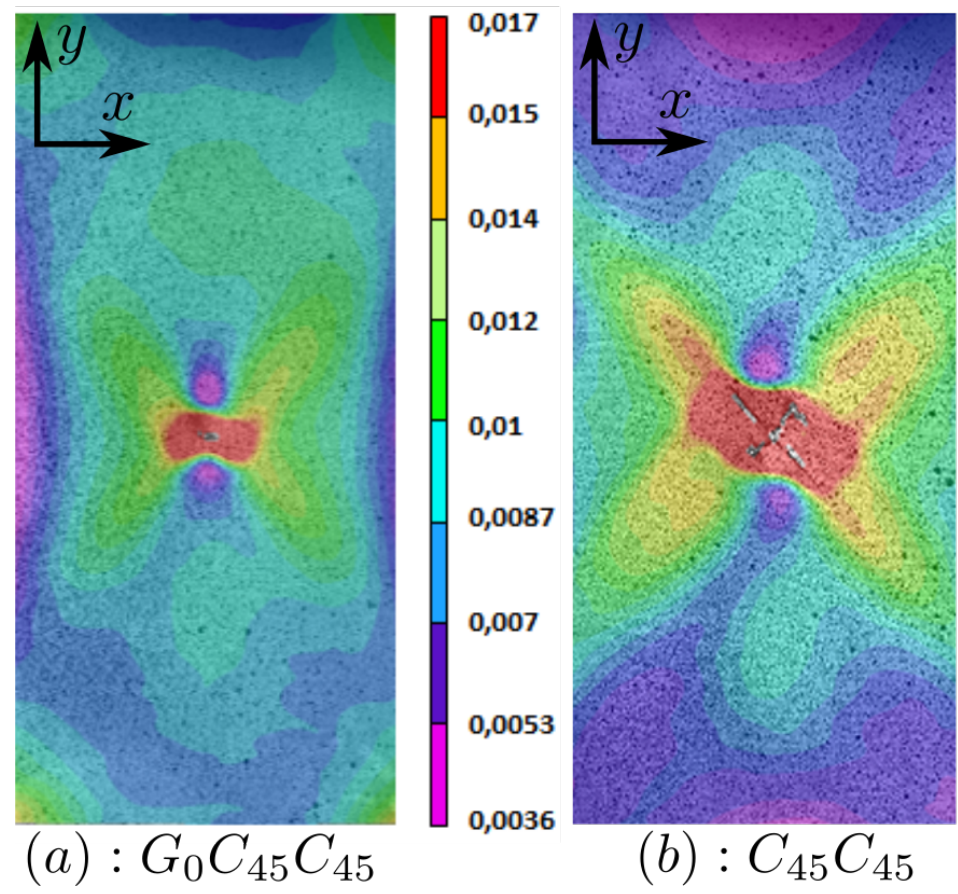

(b) : $C_{45} C_{45}$

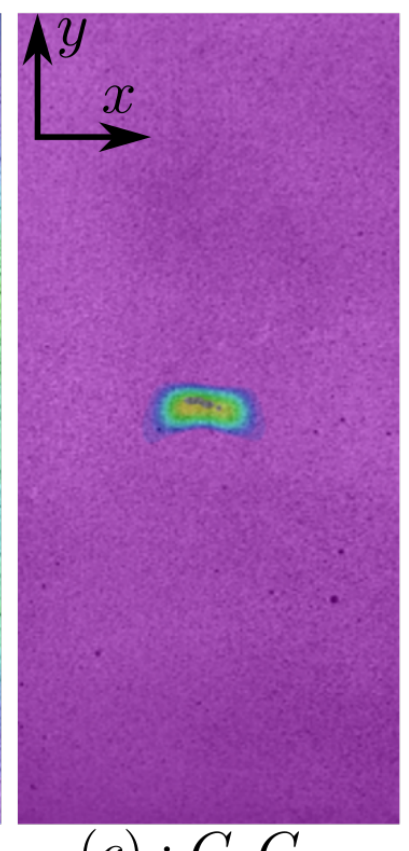

$(c): G_{0} G_{0}$

Figure 24: Strain field $\varepsilon_{y y}$ in the upper ply for a crosshead displacement of $1.5 \mathrm{~mm}$ 


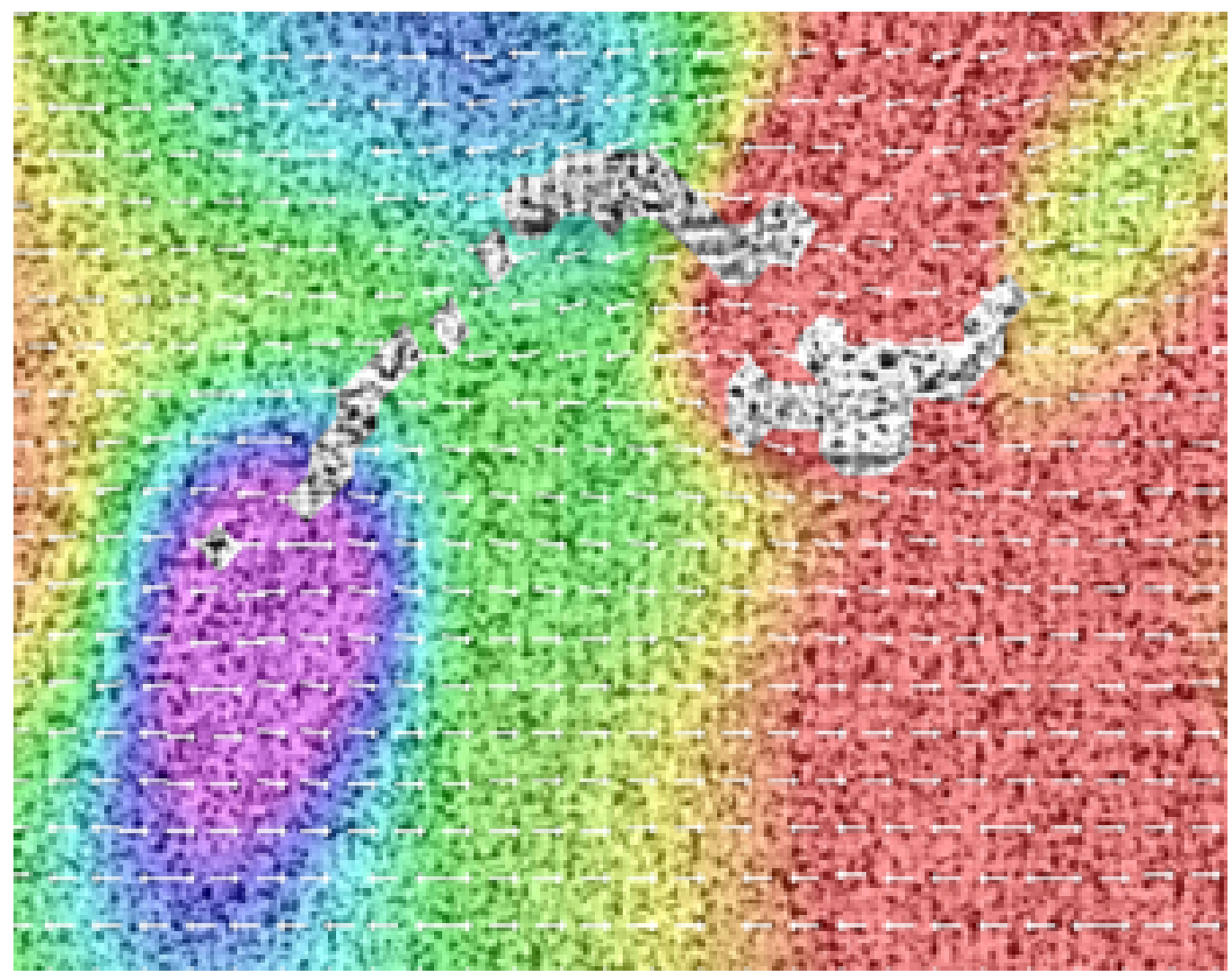

Figure 25: Strain field $\varepsilon_{x x}$ for a crosshead displacement of $2.5 \mathrm{~mm}$ in the upper ply of $G_{0} C_{45} C_{45}$ around the damaged area 


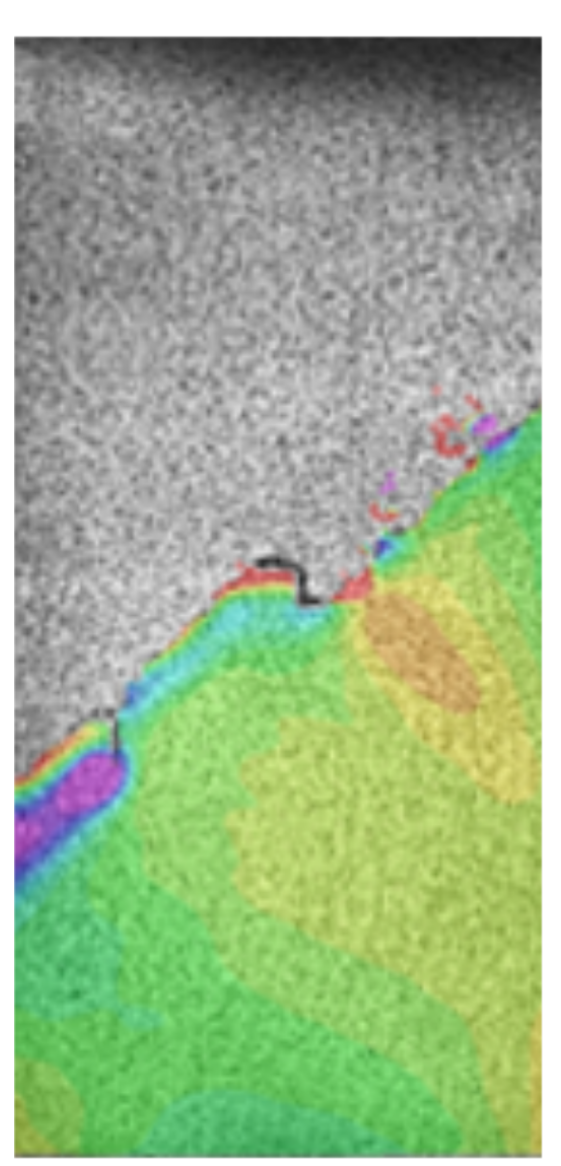

$$
\text { (a) }: \operatorname{Top}\left(G_{0}\right)
$$

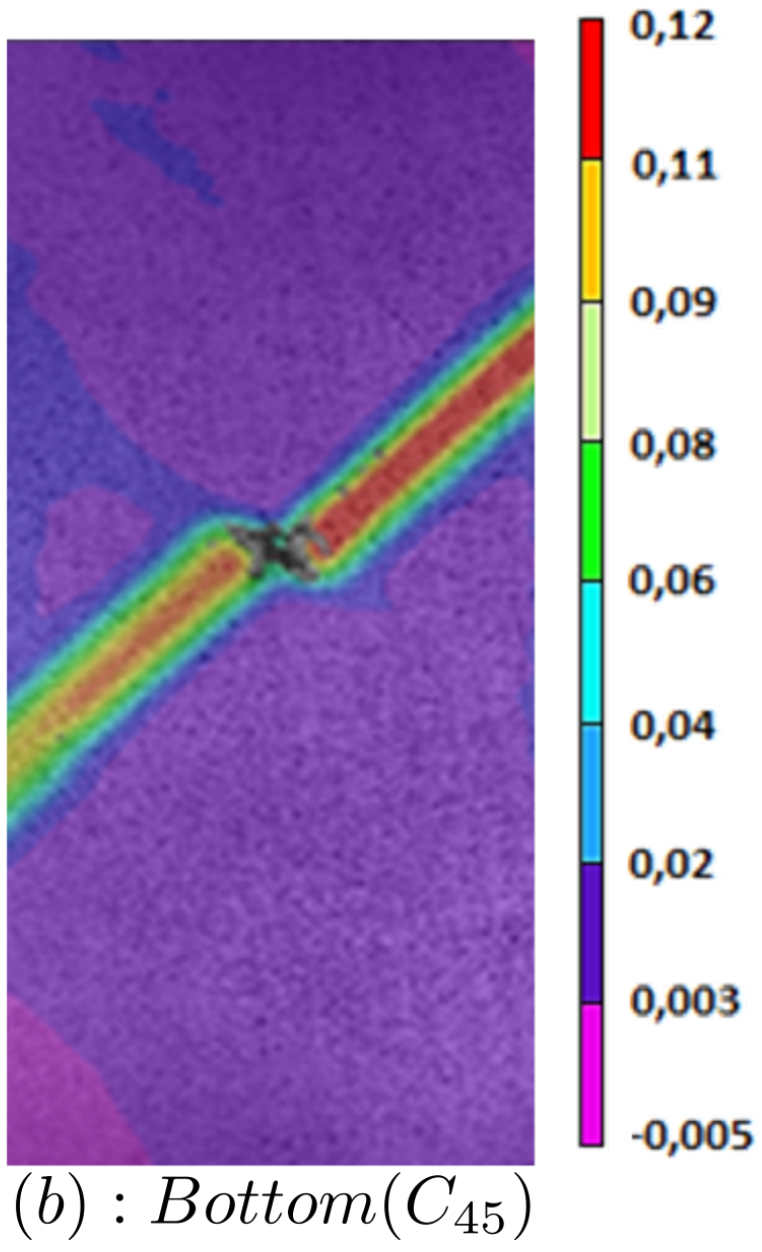

Figure 26: Strain field $\varepsilon_{y y}$ at the break of the glass ply of $G_{0} C_{45} C_{45}$

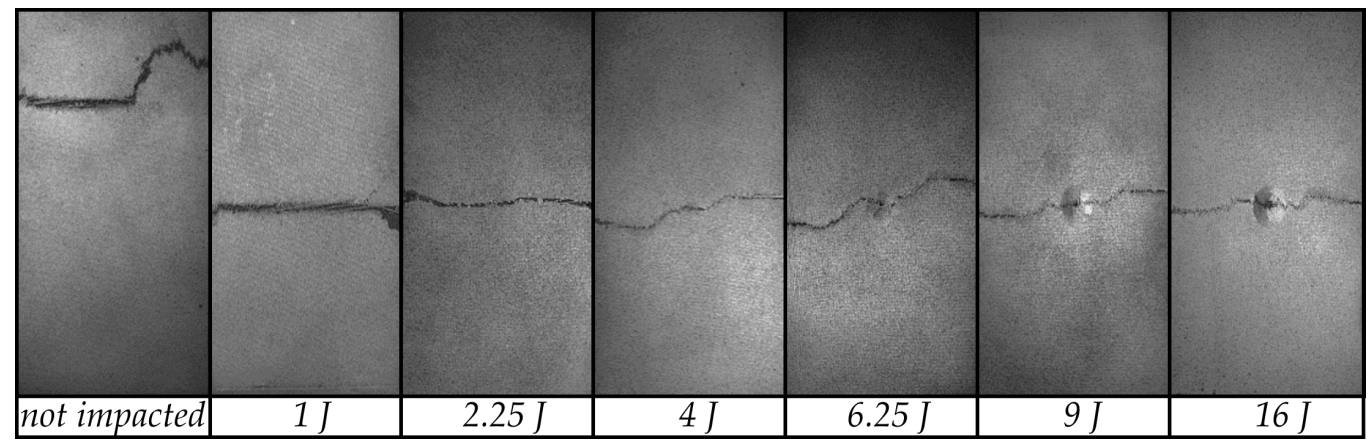

Figure 27: Fracture surfaces for post-impact quasi-static tensile tests of $G_{0} C_{45} C_{0}$ 


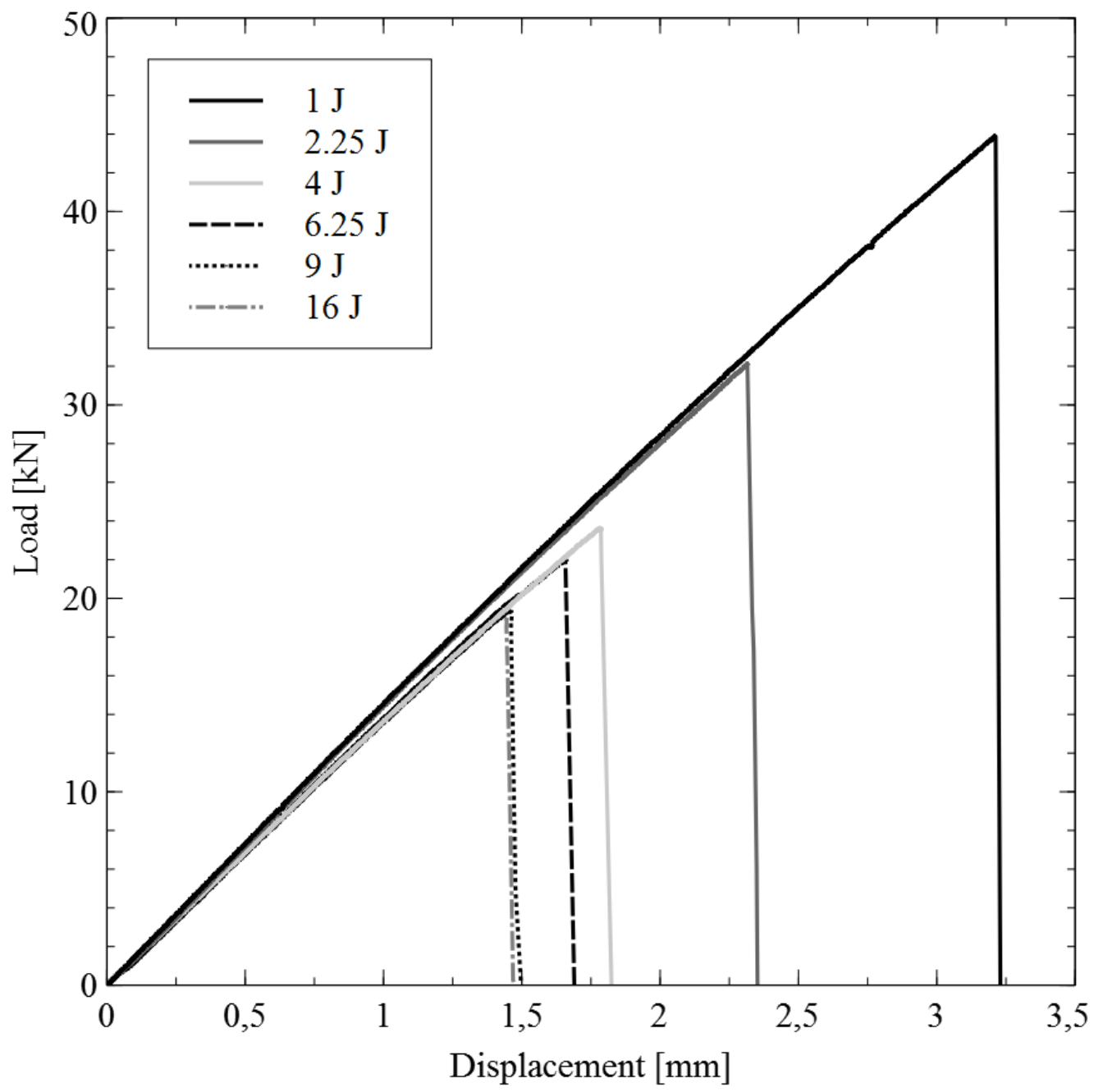

Figure 28: Load - Crosshead displacement curves for post-impact quasi-static tensile tests of $G_{0} C_{45} C_{0}$ 

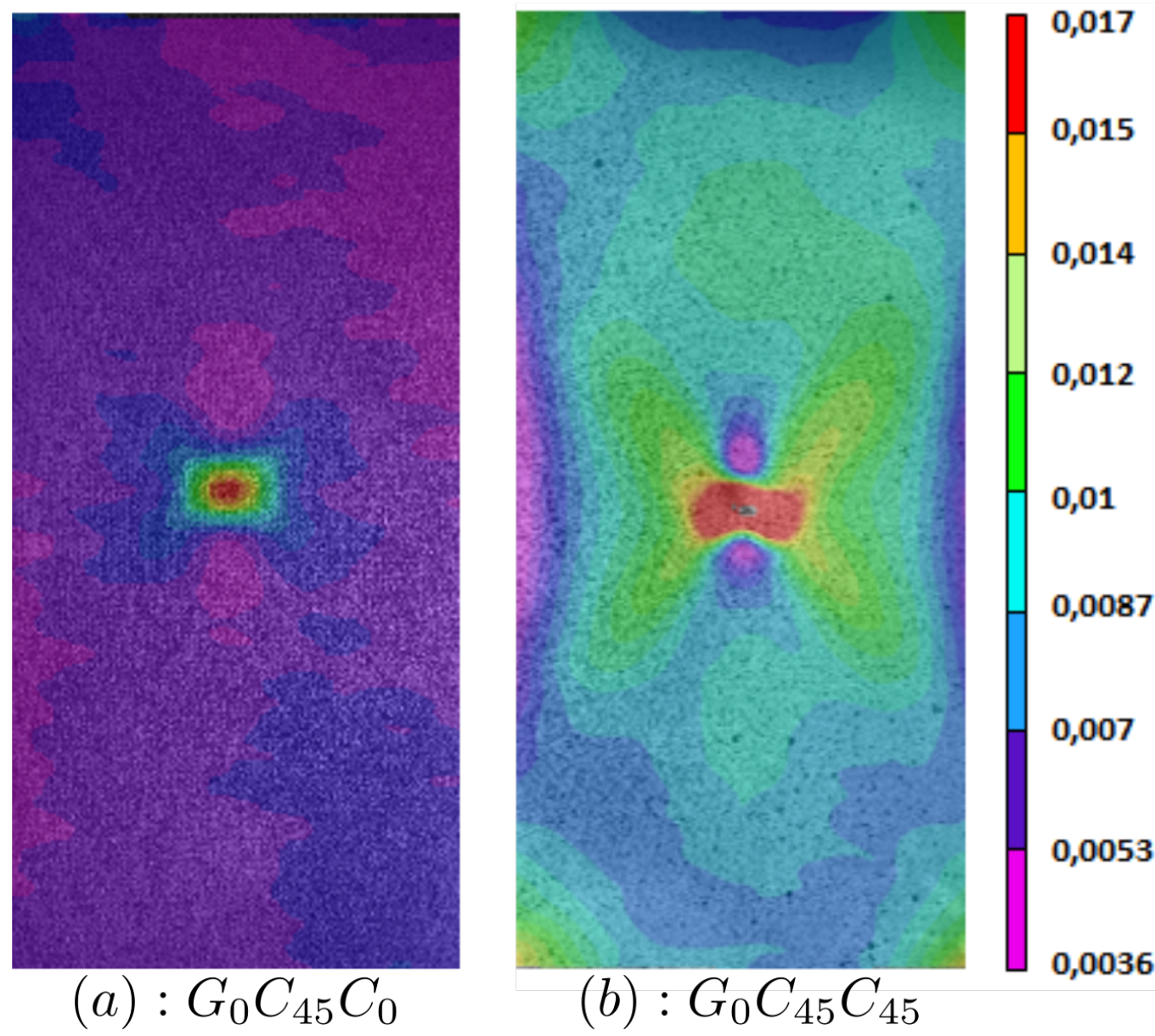

Figure 29: Strain field $\varepsilon_{y y}$ in the upper ply for a crosshead displacement of $1.5 \mathrm{~mm}$ for the $2.25 \mathrm{~J}$ case 

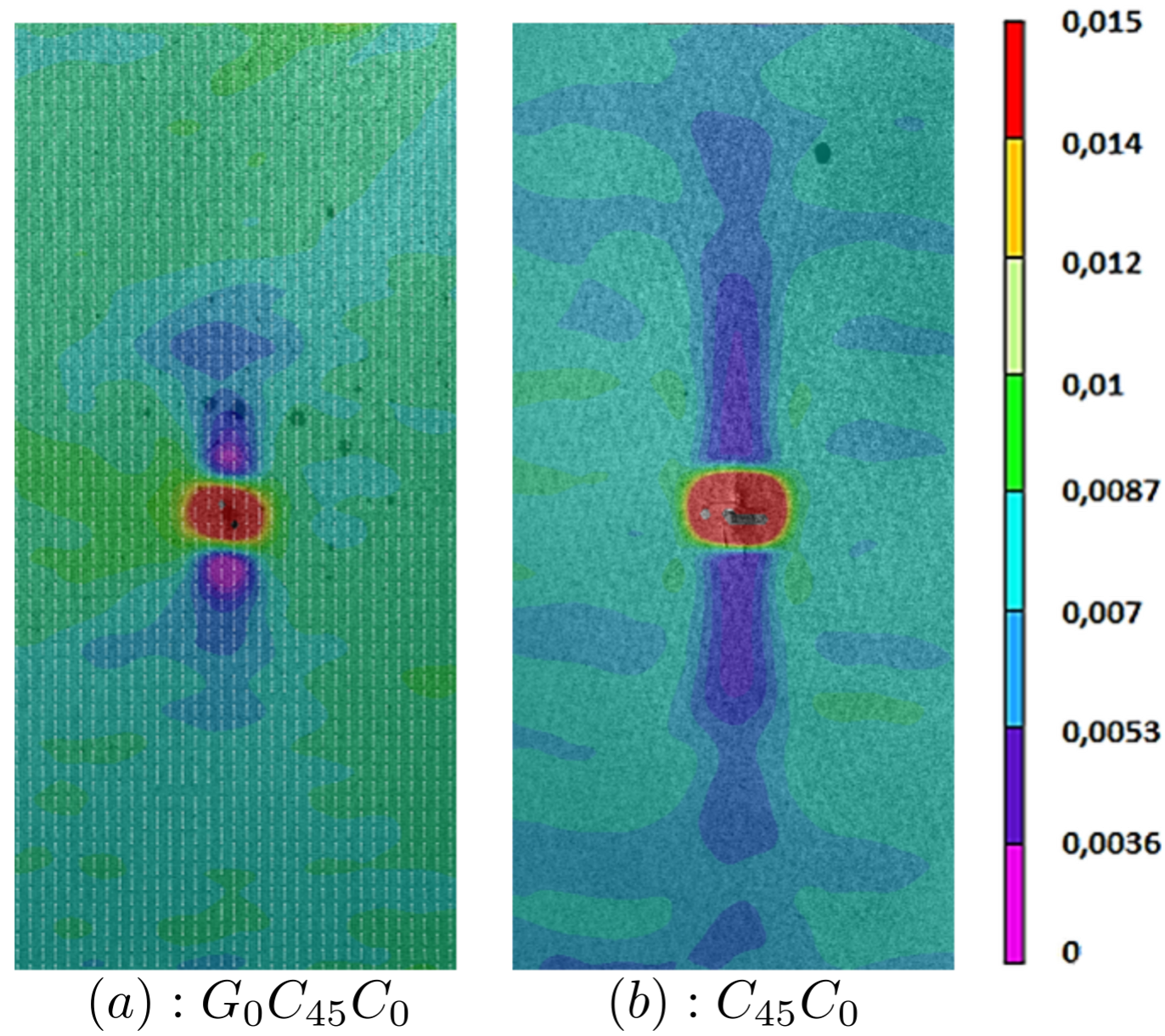

Figure 30: Strain field $\varepsilon_{y y}$ in the bottom ply for a crosshead displacement of $1.5 \mathrm{~mm}$ for the $2.25 \mathrm{~J}$ case 

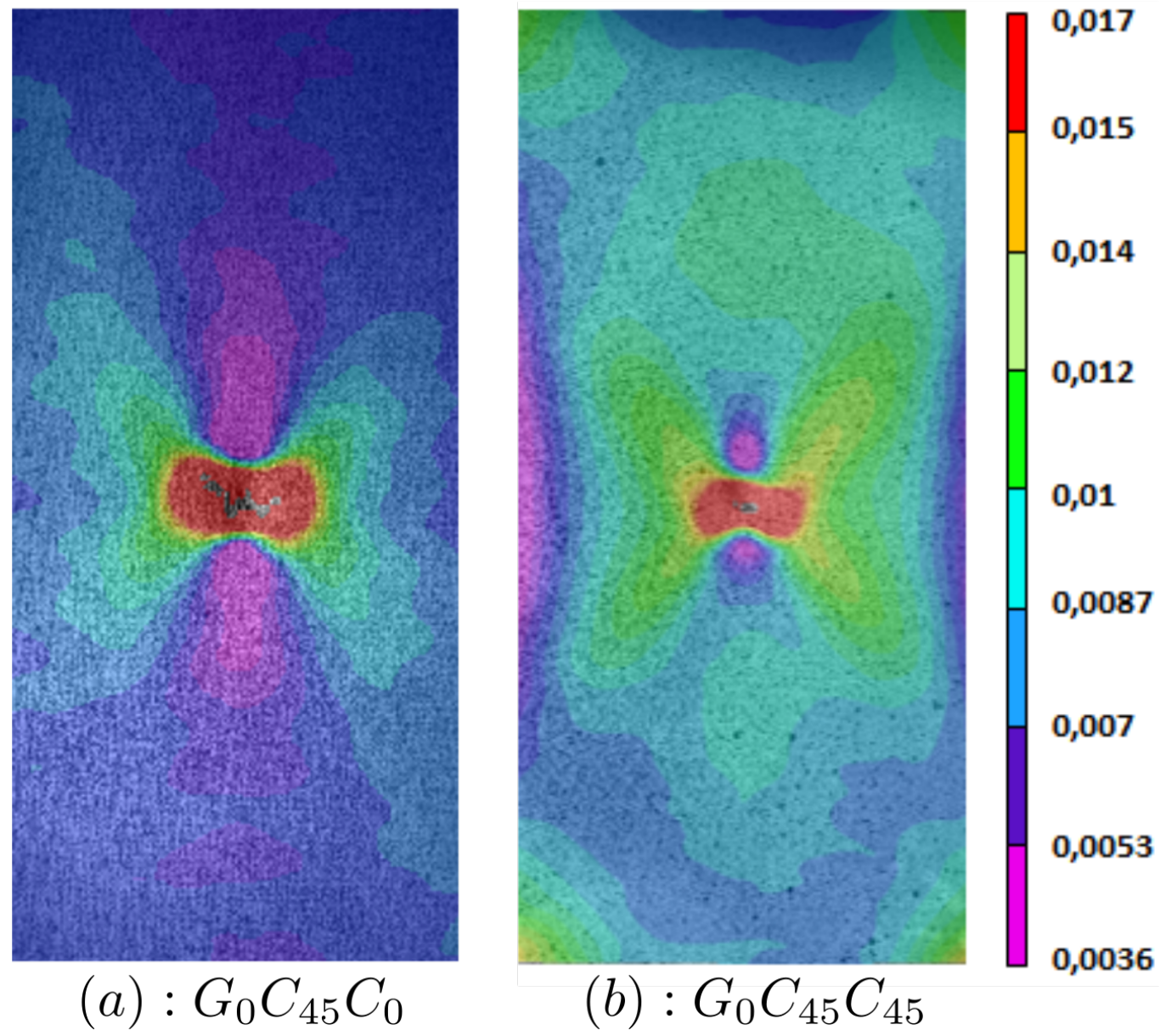

Figure 31: Strain field $\varepsilon_{y y}$ in the upper ply for a crosshead displacement of $1.5 \mathrm{~mm}$ for the $6.25 \mathrm{~J}$ case 


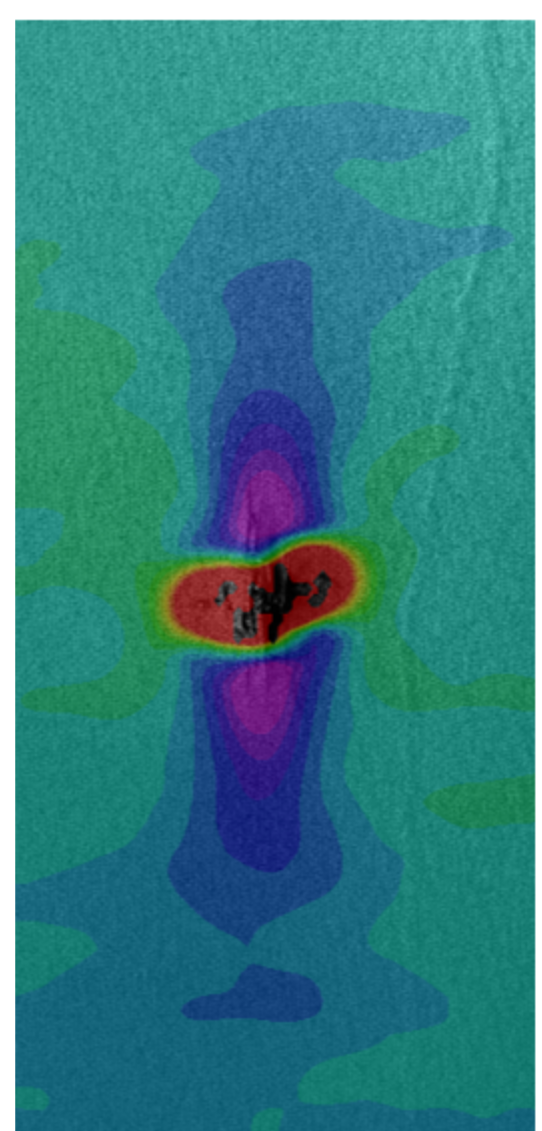

$$
\text { (a) : } G_{0} C_{45} C_{0}
$$

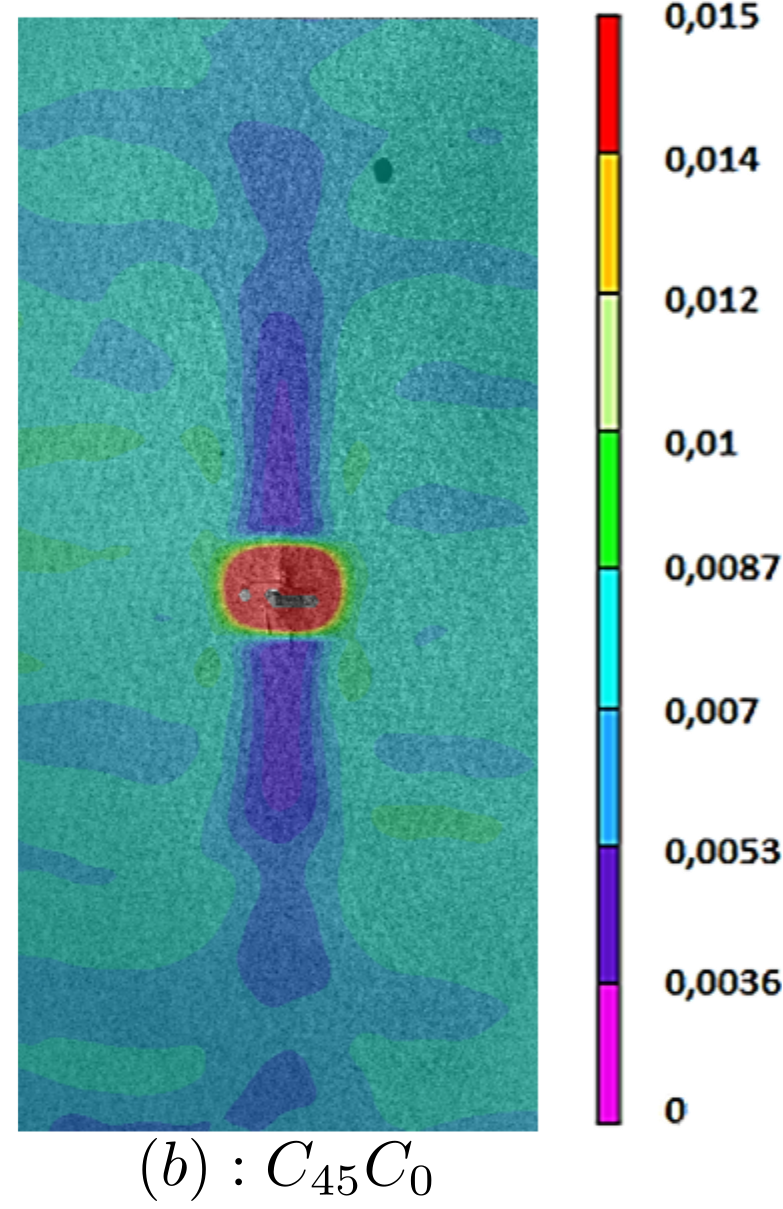

Figure 32: Strain field $\varepsilon_{y y}$ in the bottom ply for a crosshead displacement of $1.5 \mathrm{~mm}$ for the $6.25 \mathrm{~J}$ case 


\begin{tabular}{|c|c|c|c|}
\hline Configuration & Lower ply & Middle ply & Upper ply \\
\hline$G_{0} C_{45} C_{45}$ & Glass $(0 / 90)^{\circ}$ & Carbon $\pm 45^{\circ}$ & Carbon $\pm 45^{\circ}$ \\
$G_{0} C_{45} C_{0}$ & Glass $(0 / 90)^{\circ}$ & Carbon $\pm 45^{\circ}$ & Carbon $(0 / 90)^{\circ}$ \\
\hline
\end{tabular}

Table 1: Configurations for hybrid laminates

\begin{tabular}{|c|c|c|}
\hline Configuration & Lower ply & Upper ply \\
\hline$C_{0} C_{0}$ & Carbon $(0 / 90)^{\circ}$ & Carbon $(0 / 90)^{\circ}$ \\
$C_{45} C_{45}$ & Carbon $\pm 45^{\circ}$ & Carbon $\pm 45^{\circ}$ \\
$C_{45} C_{0}$ & Carbon $(0 / 90)^{\circ}$ & Carbon $\pm 45^{\circ}$ \\
$G_{0} G_{0}$ & Glass $(0 / 90)^{\circ}$ & Glass $(0 / 90)^{\circ}$ \\
\hline
\end{tabular}

Table 2: Configurations for single-material laminates 


\begin{tabular}{|c|c|c|}
\hline & Initial velocity & Energy of impact \\
\hline \multirow{6}{*}{ 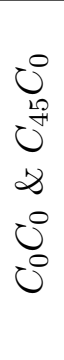 } & $1 \mathrm{~m} / \mathrm{s}$ & $1 \mathrm{~J}$ \\
\hline & $1.5 \mathrm{~m} / \mathrm{s}$ & $2.25 \mathrm{~J}$ \\
\hline & $1.75 \mathrm{~m} / \mathrm{s}$ & $3 \mathrm{~J}$ \\
\hline & $2 \mathrm{~m} / \mathrm{s}$ & $4 \mathrm{~J}$ \\
\hline & $2.5 \mathrm{~m} / \mathrm{s}$ & $6.25 \mathrm{~J}$ \\
\hline & $3 \mathrm{~m} / \mathrm{s}$ & $9 \mathrm{~J}$ \\
\hline \multirow{5}{*}{$U_{U^{12}}^{\frac{12}{f+}}$} & $1.5 \mathrm{~m} / \mathrm{s}$ & $2.25 \mathrm{~J}$ \\
\hline & $1.75 \mathrm{~m} / \mathrm{s}$ & $3 \mathrm{~J}$ \\
\hline & $2 \mathrm{~m} / \mathrm{s}$ & $4 \mathrm{~J}$ \\
\hline & $2.5 \mathrm{~m} / \mathrm{s}$ & $6.25 \mathrm{~J}$ \\
\hline & $3 \mathrm{~m} / \mathrm{s}$ & $9 \mathrm{~J}$ \\
\hline \multirow{5}{*}{ 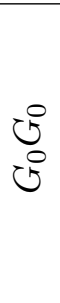 } & $2 \mathrm{~m} / \mathrm{s}$ & $4 \mathrm{~J}$ \\
\hline & $2.25 \mathrm{~m} / \mathrm{s}$ & $5 \mathrm{~J}$ \\
\hline & $2.4 \mathrm{~m} / \mathrm{s}$ & $5.75 \mathrm{~J}$ \\
\hline & $2.5 \mathrm{~m} / \mathrm{s}$ & $6.25 \mathrm{~J}$ \\
\hline & $3 \mathrm{~m} / \mathrm{s}$ & $9 \mathrm{~J}$ \\
\hline \multirow{6}{*}{ 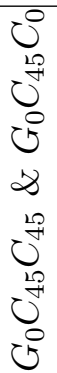 } & $1 \mathrm{~m} / \mathrm{s}$ & $1 \mathrm{~J}$ \\
\hline & $1.5 \mathrm{~m} / \mathrm{s}$ & $2.25 \mathrm{~J}$ \\
\hline & $2 \mathrm{~m} / \mathrm{s}$ & $4 \mathrm{~J}$ \\
\hline & $2.5 \mathrm{~m} / \mathrm{s}$ & $6.25 \mathrm{~J}$ \\
\hline & $3 \mathrm{~m} / \mathrm{s}$ & $9 \mathrm{~J}$ \\
\hline & $4 \mathrm{~m} / \mathrm{s}$ & $16 \mathrm{~J}$ \\
\hline
\end{tabular}

Table 3: Different impact energies tested for $C_{0} C_{0}, C_{45} C_{45}, C_{45} C_{0}, G_{0} G_{0}, G_{0} C_{45} C_{45}$ and $G_{0} C_{45} C_{0}$ 